\title{
EL SEÑORÍO DE LOS SILVA DE CIFUENTES EN LOS CONCEJOS DE ATIENZA Y MEDINACELI (1431-1779)
}

\author{
Nicolás Ávila SEOANE \\ Universidad Complutense de Madrid
}

\begin{abstract}
Resumen
Historia del señorío de Cifuentes desde la egresión inicial llevada a cabo por Alfonso $\mathrm{X}$, hasta el fin del régimen señorial. Destaca el periodo a partir de la segunda salida de la Corona por la donación en 1431 a Juan de Silva, donde hay abundantes citas textuales de documentación inédita siempre contrastadas con la bibliografía que queda en algunos casos desmentida. Ya en el siglo XVII se analizan dos pleitos de sucesión con la lista exhaustiva de los pretendientes al señorío y los fundamentos genealógicos en que se apoyaban.
\end{abstract}

Palabras clave: Señoríos. Baja Edad Media. Edad Moderna. Nobleza. Cifuentes. Silva.

\section{Summary}

History of the manor of Cifuentes from its initial gift by Alfonso $X$ to the end of the lordly régime. It throw into relief the period starting on the second leaving from the royal lands because of the gift in 1431 to Juan de Silva, where there are many textual quotations from unpublished documents always contrasted with the bibliography which sometimes comes refuted. Already in 17 th century are analyzed two successorial lawsuits with the complete catalogue of the manor's pretenders and the genealogical foundations in which were supported.

Key words: Manors. Late Middle Ages. Modern Times. Nobility. Cifuentes. Silva.

El señorio de Cifuentes, que acabó ocupando una amplia zona del sur del concejo de Atienza y extendiéndose por el vecino de Medinaceli, tuvo su centro en la fortaleza levantada allí por don Juan Manuel («Era MCCCLXII [...] eodem mense [madii] incepit dominus Joannes castellum de Centfontibus»') y sobre la cual trataron Layna

\footnotetext{
1. En el Cronicón de don Juan Manuel que se transcribe en FLÓREZ, Enrique (1908 [1754; segunda edición]): España Sagrada. Theatro geográphico-histórico de la Iglesia de España. Origen, divisiones y límites
} 
Serrano y Herrera Casado ${ }^{2}$. En este artículo, parte de un trabajo en curso que abarcará toda la extremadura castellana, estudio cómo a partir de la inicial donación en 1431 a Juan de Silva, primer conde de Cifuentes, él y sus descendientes desarrollaron una amplia política de compras en la zona, que les llevó a formar un extenso patrimonio sólo superado por las varias ramas de los Mendoza que dominaban el resto del concejo de Atienza y por los duques de Medinaceli.

\section{EL SEÑORÍO DE CIFUENTES ANTES DE LOS SILVA (CIRCA 1255-1431)}

Alfonso X donó Cifuentes a su querida Mayor Guillén de Guzmán aunque los historiadores no se ponen de acuerdo en la fecha de esta merced. Layna Serrano según avanzaba en sus investigaciones la fue adelantando: en Castillos de Guadalajara «hacia 1260»; en Historia de la villa de Atienza, entre 1254 y 1257, y en Historia de la villa condal de Cifuentes, en 1253 a raíz de la boda de Beatriz, hija del rey en doña Mayor, con Alfonso III de Portugal ${ }^{3}$. Juan Catalina García en los aumentos a las Relaciones de Cifuentes dice que fue después de $1254^{4}$. Julio González a pesar de que cita la Historia de Cifuentes de Layna, 1leva la merced a $1261^{5}$. Martínez Díez precisa que fue el 22 de octubre de 1255 aunque no menciona su fuente ${ }^{6}$. Caroline Mignot se pronuncia a favor de $1260^{7}$. Antonio Herrera opta por $1253^{8}$. Riesco de Iturri omite cualquier referencia cronológica9. El legajo 3329 de Osuna tampoco aclara cuándo se produjo la merced: «por auténticas escrituras de que hacen mención diferentes memoriales que corren impresos de la Casa de los Guzmanes y señaladamente del testamento que otorgó doña Mayor de Guzmán en 4 de octubre de 1262, hija que fue de don Guillén Ruiz de Guzmán y de doña María González Girón, resulta que aquella señora obtenía

de todas sus provincias. Antigüedad, traslaciones y estado antiguo y presente de sus sillas, con varias dissertaciones criticas II, 220.

2. Layna Serrano, Francisco (1994 [1933]): Castillos de Guadalajara, páginas 305 a 308 y artículo en Espinosa de los Monteros MARTín, Juan y MARTín-ARTAJo SARACHo, Luis (coords.) (1974): Corpus de castillos medievales de Castilla, páginas 112 y 113 y Herrera CASADO, Antonio (1988 [1983]): Crónica y guia de la provincia de Guadalajara, página 178 y (1989): Castillos y fortalezas de Castilla-La Mancha, página 224.

3. LAYNA SerRano, Francisco (1994 [1933]): Castillos de Guadalajara, página 304; (1945): Historia de la villa de Atienza, página 120 y (1955): Historia de la villa condal de Cifuentes (Guadalajara), página 38.

4. ORTIZ GARCía, Antonio (2002): Relaciones topográficas de la provincia de Guadalajara, edición digital.

5. GONZÁLEZ y GONZÁLEZ, Julio (1975-1976): Repoblación de Castilla la Nueva I, página 299.

6. MARTíNez DíEZ, Gonzalo (1983): Las comunidades de villa y tierra de la extremadura castellana (estudio histórico-geográfico), página 269.

7. Mignot, Caroline (1986): «Evolución de la estructura jurisdiccional en la región alcarreña (siglos XIXV)》 en Hispania XLVI, 163, página 255.

8. Herrera CASADO, Antonio (1988 [1983]): Crónica y guía de la provincia de Guadalajara, página 175 y (2000): Guía de campo de los castillos de Guadalajara, página 142.

9. RiEsCo DE ITURRI, María Begoña (1996): Nobleza y señoríos en la Castilla centro-oriental en la Baja Edad Media (siglos XIV y XV), página 679. 
los estados de Salmerón, Valdeolivas, Alcocén (sic), Cifuentes, Azañón, Viana y otros pueblos en la Alcarria» $\rangle^{10}$. Lo único seguro que puede extraerse de la documentación es que doña Mayor ya era señora de Cifuentes en septiembre de 1260 cuando dota el monasterio de Alcocer y prohíbe a los monjes que compren más heredamientos en las tierras de su señorío: «e que no puedan comprar ni ganar más desto en ninguno de míos logares de Allcoçer (sic) ni en Viana ni en Ciffuentes ni en Palacihuelos. E si lo compraren ni lo ganaren, que les no uala» ${ }^{11}$.

A la muerte de Mayor Guillén, acaecida antes de 1267 según Juan Catalina Garcia $^{12}$, heredó Cifuentes su hija Beatriz, reina de Portugal, que murió en $1303^{13}$. Caroline Mignot opina que Beatriz fue señora de Cifuentes desde 1262 por donación de su madre sin decir de dónde ha obtenido ese dato ${ }^{14}$. Recayó después en su hija la infanta Blanca de Portugal, confundida por los cifontinos más de tres siglos después, en el momento de responder al cuestionario enviado por Felipe II para elaborar las Relaciones, con Blanca de Molina: «fue de una infanta de Molina llamada doña Blanca, hija del rey don Alonso el Sabio, y por muerte de la infanta heredó a Cifuentes y a Molina y Alcocer la bienaventurada y cristianísima reina doña Maria, muger que fue del rey don Sancho el Brabo, por ser prima hermana de la infanta doña Blanca» $\rangle^{15}$. Doña Blanca decidió vender sus dominios alcarreños poco después de la subida al trono de Alfonso XI. Según la Crónica de Alfonso XI «porque la infanta doña Blanca, fija del rey de Portogal, vendió al infante don Pedro a Fuentes et a Alcocer et a Viana et a Azeñón et a Palazuelos, porque esta infanta las avía vendido primero a don Joán, fijo del infante don Manuel, et le non pagara el plazo que pusiera con ella et avía pleyto con él que si le non pagase al plazo, que las pudiese ella vender a otro. Tóvose por muy agraviado don Juan por esta compra que el infante don Pedro avía fecho et luego se envió despedir del rey et desnaturar del reino et corrió toda la tierra de Huepte et de Guadalfajara et de Fita et de toda esa tierra et robó et fizo mucho mal et mucho

10. AHN, Nobleza, Osuna, legajo 3329, expediente 1, pie 1, folio 1. El largo legajo 3329 del fondo Osuna recoge la Historia de todos los dominios de los duques del Infantado (expediente 1) y de Pastrana (expediente 2); no está fechado pero en el expediente 2 (pie 5, folio 5 vuelto) dice que se buscó un documento sobre el mayorazgo del adelantado de Cazorla Pedro Hurtado de Mendoza en el Archivo de Simancas en 1745 , por lo que la redacción ha de ser posterior.

11. AHN, Clero, Secular y regular, carpeta 566, documento 5 .

12. ORTIZ GARCIA, Antonio (2002): Relaciones topográficas de la provincia de Guadalajara, edición digital, aumentos de Alcocer.

13. Layna Serrano, Francisco (1994 [1933]): Castillos de Guadalajara, página 304 y (1955): Historia de la villa condal de Cifuentes (Guadalajara), página 40; GONZÁLEZ y GONZÁLEZ, Julio (1975-1976): Repoblación de Castilla la Nueva I, página 299; Herrera CASAdo, Antonio (1988 [1983]): Crónica y guia de la provincia de Guadalajara, página 175 y RIESCO DE ITURRI, María Begoña (1996): Nobleza y señorios en la Castilla centro-oriental en la Baja Edad Media (siglos XIV y XV), página 679.

14. MIGNOT, Caroline (1986): «Evolución de la estructura jurisdiccional en la región alcarreña (siglos XIXV)» en Hispania XLVI, 163, página 255

15. OrTIZ GARCía, Antonio (2002): Relaciones topográficas de la provincia de Guadalajara, edición digital. 
daño en todos esos logares» ${ }^{16}$. La propia crónica fecha este pasaje «en el tercero año del regnado deste rey don Alfonso, que comenzó en el mes de setiembre en la Era de mill et trescientos et quarenta et nueve años et andaba la nascencia de Nuestro Señor Jesu Christo en mill et trescientos et once años» aunque Fernando IV no murió hasta 1312 y el tercer año del reinado de don Alfonso empezó por tanto en septiembre de 1314, problema cronológico que afecta a las crónicas de ambos monarcas y que ya puso de manifiesto su editor Cayetano Rosell, debiéndonos regir siempre por el año del reinado ${ }^{17}$.

El relato de los problemas de don Juan Manuel con el infante Pedro es la primera referencia a la venta de Cifuentes que aparece en la crónica y no aclara cuándo se había producido el acuerdo entre doña Blanca y el hijo del infante Manuel. Es posible que fuera varios años antes, aún en el reinado de Fernando IV, pues en abril de 1312 don Juan Manuel escribía a Jaime II de Aragón, suegro de los dos compradores, pidiéndole dinero porque ya la infanta Blanca estaba pensando en echarse atrás y tenía que pagar un plazo en mayo: «sepades que después que enuié a uos a Alfonso Martines de Aguilar sobre fecho de la compra que fise de la infanta donna Blanca, que me llegó mandado de Johán Garcia de Alcabdet, mío vasallo que es en casa del rey de Castiella, en cómo la infanta dicha es rrepentida desta uendida que me fiso (espacio en blanco) poner para desfacer la uendida que no (espacio en blanco) faser si yo falleçiese alguna cosa de las posturas que con ella he. Et sennor, por cosas que me acaesçieron de la mi fasienda que oue de faser segund conuusco lo fablé, non he complimiento para la paga que he de faser agora en el mes de mayo et asi tengo la dicha compra en muy grand auentura. Et porque este fecho es mucho apresurado et non lo podiendo escusar, enuio a uos a don Rremón Durche, mio vasallo, et a frey Jaymes, mio confesor. Porque uos pido merçed, sennor, que a tal tiempo como éste tengades por bien de me acorrer para esto porque por uos sea heredado» ${ }^{18}$.

La nueva venta de Blanca de Portugal por el incumplimiento del plazo provocó como digo el enfrentamiento entre el infante Pedro y don Juan Manuel. Ambos 1legaron a un primer acuerdo cuyas cláusulas estaban ya escritas el 2 de mayo de 1314 pero que aún tardaron un tiempo en firmar ${ }^{19}$. No es posible asegurar en qué momento se produjo la ratificación de este pacto porque sólo lo conocemos por una carta escrita a Jaime II por el infante Pedro que carece de fecha pero tiene una referencia que la hace posterior al 24 de junio pues dice que don Juan Manuel tras el acuerdo «vino a Pennafiel seyendo yo en Burgos, agora por este Sant Johán, et enbiome mover guerra ${ }^{20}$ Además

16. Crónica de Alfonso XI en Crónicas de los reyes de Castilla (edición de la BAE) I, página 178.

17. Crónica de Fernando $I V$ en Crónicas de los reyes de Castila (edición de la BAE) I, notas de las páginas 119 y 167.

18. Documento transcrito en GIMÉnez SOLER, Andrés (1932): Don Juan Manuel. Biografia y estudio critico, página 408 .

19. GIMÉNEZ SOLER, Andrés (1932): Don Juan Manuel. Biografia y estudio critico, página 55.

20. Transcripción en GIMÉnEZ SOLER, Andrés (1932): Don Juan Manuel. Biografia y estudio critico, páginas 449 y 450 . 
el 22 de agosto don Pedro vendió Palazuelos, uno de los lugares en disputa, al obispo de Sigüenza ${ }^{21}$, por lo que para entonces ya estaría firmado el acuerdo. Giménez Soler dice que don Juan Manuel, tras retirarse un tiempo a Peñafiel, reinició las hostilidades y atacó Berlanga de Duero, señorío del infante, en el mes de octubre ${ }^{22}$. Por tanto hay que situar el pacto hacia junio de 1314, unos tres meses antes de la fecha en que la Crónica de Alfonso XI aún mantiene enfrentados a ambos personajes. Dice don Pedro en la carta al rey de Aragón que se acordó «que yo que fincasse con Cifuentes e con las pennas de Vianna. Et él que fincasse con Alcoçer. E los otros lugares que fincauan que los partiéssemos por medio». El acuerdo definitivo llegó en febrero de 1316 en Cuéllar, donde don Juan Manuel y el infante Pedro decidieron repartirse por mitad los lugares y el pago comprometido con Blanca de Portugal. Cifuentes fue adjudicado a don Juan Manuel y por eso, como bien apunta Layna, el Cronicón de don Juan Manuel dice que en 1317 el magnate castellano recuperó Cifuentes ${ }^{23}$ : «Era MCCCLV recuperavit dominus Joannes Centum Fontes in madio» ${ }^{24}$.

Los intereses de Jaime II en estas tierras y otras también próximas a la frontera de Aragón eran claros al menos desde agosto de 1310 cuando comenzó a tratar el matrimonio de su hija María con el infante Pedro pues don Jaime quería que su yerno recibiera de Fernando IV con motivo de la boda amplios dominios en esa zona de Castilla: «esto es lo que el rey dAragón entiende que sea heredado don Pedro: primeramente Molina con todo el condado como lo ovieron los condes de Molina e a esto faga el arcidiano [uno de los negociadores] todo su poder. E si esto non se puede fazer, demande Medinaçélim con todos sus términos e pertinençias, Alcoçer, Çifuentes, Salmerón, Viana, Serón, Montagudo, Deça, Çahela (sic por Çihuela), cada uno destos lugares con todos sus términos e pertinençias $\rangle^{25}$; lo mismo recoge Zurita: «pedía que le diese a Molina con todo el condado como lo habian tenido los condes que fueron de Molina y, cuando esto no se pudiese acabar, que le diese Medinacelin, Alcocer, Cifuentes, Salmerón, Viana, Serón, Montagudo, Deza y Cihuela con todos sus términos y jurisdicciones. [...] Ofrecía el rey de Castilla de dar a su hermano las villas de Almazán y Montagudo y Alcocer, Cifuentes, Viana, Serón y Deza con sus aldeas; y porque no se podian luego entregar Alcocer, Cifuentes y Viana porque las tenía la infanta doña Blanca y Deza y Serón estaban aún en poder de don Alonso, hijo del infante don Fernando, daba el rey de Castilla a Berlanga con sus aldeas para que la tuviese el

21. El documento en Minguella y ARnedo, Toribio (1910-1913): Historia de la diócesis de Sigüenza y de sus obispos, II, páginas 425 a 428.

22. GIMÉNEZ SOLER, Andrés (1932): Don Juan Manuel. Biografía y estudio crítico, página 56.

23. LAYNA SERrano, Francisco (1955): Historia de la villa condal de Cifuentes (Guadalajara), página 59.

24. Flórez, Enrique (1908 [1754; segunda edición]): España Sagrada. Theatro geográphico-histórico de la Iglesia de España. Origen, divisiones y limites de todas sus provincias. Antigüedad, traslaciones y estado antiguo y presente de sus sillas, con varias dissertaciones críticas II, página 218.

25. Los capítulos de la embajada de Domingo García de Echauri sobre este matrimonio están transcritos en GIMÉNIZ SOLER, Andrés (1932): Don Jian Manuel. Biografia y estudio critico, páginas 381 y 382. 
infante hasta que se le entregasen $\rangle^{26}$. En 1311 se casaron Maria y Pedro. Las capitulaciones definitivas establecen que «el rey de Castiella dará al infante don Pedro, su hermano, la villa de Almaçán con sus aldeas e términos, Salmerón, Montagudo e sus aldeas e Alcoser, Cifuentes, Viana, Serón e Deça. E porque luego el rey de Castilla non puede vender Alcoçer, Cifuentes e Viana, que tiene la infanta donna Blanca, e Deça e Serón, que tiene don Alfonso, dará en penyos Berlanga con sus aldeas, derechos e pertinençias, que los tenga el infante don Pedro fasta que le aya el rey de Castiella entregamente (sic) todos los dichos lugares $\rangle^{27}$. Pero en 1311 también se casó don Juan Manuel con Constanza, otra hija de Jaime II, y no dudó en buscar el favor de su suegro. La Crónica de Fernando IV opina que el señorío del infante Pedro sobre Berlanga de Duero estuvo motivado por cambios de villas y cargos en los que también participó don Juan Manuel: «e el rey, teniendo que por este oficio tendria a este don Juan de su ayuda, ovo de rogar al infante don Pedro, su hermano, que dejase el mayordomazgo; e porque estonce avía el rey prometido a este infante don Pedro de le dar a Almazán e Berlanga por heredad e non ge las avia aún dado, ovo a consentir el infante don Pedro en dejar este oficio por aver estas dos villas por heredad. E estonce el rey dio el mayordomazgo a don Juan, fijo del infante don Manuel»; «e luego el infante don Pedro, su hermano del rey, le demandó que le entregase a Almazán e a Berlanga que le avia dado por heredad; e porque era de la reina doña María, su madre, ovolo a fablar con ella ante e púsogelo a placer e diole por ella en camio a Arévalo; é estonce entregó al infante don Pedro a Almazán e a Berlanga e a Monteagudo e a Deza»; al referir el matrimonio de Pedro y María no dice nada de los bienes que recibieron ${ }^{28}$.

El padre Minguella fecha la venta de Cifuentes, Alcocer y Palazuelos en 1315 ó $1316^{29}$. Los autores posteriores que han estudiado la venta de Cifuentes, aunque mucha documentación fue publicada por Giménez Soler en 1932 o pertenece a las crónicas, son muy parcos al referirse a ella. Layna fue el más prolijo al investigar el misterioso recuperauit del Cronicón de don Juan Manuel, defendiendo en todas sus obras que el magnate castellano compró Cifuentes poco después de la muerte de Fernando $\mathrm{IV}^{30}$. Juan Catalina García en los aumentos a las Relaciones de Cifuentes sólo dice que «según las no muy directas referencias que conocemos, parece que en 1317 ya habia adquirido don Juan Manuel Cifuentes, Val de San Garcia y Palazuelos (junto

26. CANELlas LóPez, Ángel (1970-1977): Anales de la Corona de Aragón compuestos por Jerónimo Zurita, cronista de dicho reino II, página 739.

27. GimÉNEZ SOLER, Andrés (1932): Don Juan Manuel. Biografia y estudio critico, páginas 385 y 386 transcribe estas capitulaciones definitivas.

28. Crónica de Fernando $V$ en Crónicas de los reyes de Castilla (edición de la BAE) I, páginas 165, 167 y 169 .

29. Minguella y ARnedo, Toribio (1910-1913): Historia de la diócesis de Sigüenza y de sus obispos III, página 660.

30. Layna Serrano, Francisco (1994 [1933]): Castillos de Guadalajara, página 304; (1945): Historia de la villa de Atienza, página 148 y (1955): Historia de la villa condal de Cifuentes (Guadalajara), página 59. 
a Sigüenza) por compra hecha a la infanta y señora de Las Huelgas» ${ }^{31}$. Ángel Luis Molina declara que la venta fue en 1317 y que el dinero lo puso Jaime II $^{32}$. Caroline Mignot y Antonio Herrera datan la venta en 1317 sin dar explicaciones ${ }^{33}$. Riesco de Iturri sólo se refiere a que los dominios de Blanca de Portugal acabaron en manos de don Juan Manuel y don Pedro ${ }^{34}$.

La documentación relativa al señorío de Cifuentes donado a Mayor Guillén de Guzmán, heredado por Beatriz y Blanca y comprado por don Juan Manuel sólo recoge además de dicha villa el lugar de Val de San García. Cuando en 1431 se haga la merced a Juan de Silva de la tierra de Cifuentes ésta incluirá también Fuentepinilla, Trillo y Valderrebollo. No sé si Fuentepinilla y Valderrebollo se incluirían también en la donación de Alfonso X a doña Mayor pero Trillo desde luego no pues fue comprado por don Juan Manuel siendo ya señor de Cifuentes ${ }^{35}$.

31. OrTiz García, Antonio (2002): Relaciones topográficas de la provincia de Guadalajara, edición digital.

32. Molina Molina, Ángel Luis (1982): «Los dominios de don Juan Manuel» en Don Juan Manuel. VII centenario, página 220 .

33. Mignor, Caroline (1986): «Evolución de la estructura jurisdiccional en la región alcarreña (siglos XIXV)» en Hispania XLVI, 163, página 255 y Herrera CASADO, Antonio (1988 [1983]): Crónica y guía de la provincia de Guadalajara, páginas 175 y 176 y (2000): Guía de campo de los castillos de Guadalajara, página 143.

34. RiesCo de ItURRI, María Begoña (1996): Nobleza y señorios en la Castilla centro-oriental en la Baja Edad Media (siglos XIV y XV), página 679.

35. Francisca Pérez, heredera de su hermano Juan Garcia de Trillo, había tomado posesión de Trillo en 1313 tras largos pleitos sucesorios (Layna SerRano, Francisco (1955): Historia de la villa condal de Cifuentes (Guadalcijara), página 61; Herrera CASADO, Antonio (1988 [1983]): Crónica y guía de la provincia de Guadalajara, página 380 y ORTIz GARCía, Antonio (2002): Relaciones topográficas de la provincia de Guadalajara, edición digital): «sábado veynt dias de octubre Era de mill e tresientos e cinquenta e un año. Este día seyendo llegado el conceio de Trillo, veno Françisca Pérez, fija que fue de don Pero Garcia de Trillo et muger que es de Gil Peres de Ssant Esteuan, et dixo al dicho conçeio en el dicho logar de Trillo que ella que vinie a entrar e apoderarsse e tomar la posesión del señorio de Trillo assi como ge la dexara el dicho su padre e Johán Garcia su hermano. [...] Et el dicho conçeio dixieron que verdat era e así fueran sus señores e pasara todo como ella disíe et pues su madrre e su hermano eran finados que ellos nunca tan buen dia vieran como rreçibir a ella por señora, que era fija de su señor natural e lo auía ella de auer por derecho e non otro ninguno. Et sobresto besáronle la mano e recibiéronla por señora et prometieron de guardarle señorio así como a su señora natural) (Archivo Municipal de Cifuentes, pergaminos, documento 50). Caroline Mignot, Herrera Casado y Riesco de Iturri dicen que Sancha, Mayor y Toda, hijas de doña Francisca, vendieron a don Juan Manuel el señorío de Trillo en 1325 (MiGNOT, Caroline (1986): «Evolución de la estructura jurisdiccional en la región alcarreña (siglos XI-XV)» en Hispania XLVI, 163, páginas 256 y 257; HERRERA CASADO, Antonio (1988 [1983]): Crónica y guía de la provincia de Guadalajara, página 380 y RIESCO DE ITURRI, María Begoña (1996): Nobleza y señorios en la Castilla centro-oriental en la Baja Edad Media (siglos XIV y XV), páginas 680 y 724-725). Pero como bien señalan Layna y Juan Catalina García ya doña Francisca había vendido con anterioridad Trillo a don Juan Manuel y el 19 de marzo de 1325 Sancha, Mayor y Toda, sus hijas, ratificaron esta venta (LAYNA SERRANO, Francisco (1955): Historia de la villa condal de Cifientes (Guadalajara), páginas 61 y 62 y aumentos de Trillo de Juan Catalina en ORTIZ GARCÍA, Antonio (2002): Relaciones topográficas de la provincia de Guadalajara, edición digitai): «[sepan quantos esta] carta 
En torno a 1325 Alfonso XI se vio obligado a negociar su boda con Constanza Manuel, hija de don Juan Manuel, para garantizarse su adhesión. Debió ser por entonces cuando padre e hija compartirían el señorío de Cifuentes: doña Constanza llama «sus vasallos» a los cifontinos y dice «la my villa de Çiffuentes» al confirmar el 18 de diciembre de ese año un privilegio dado en 1296 por Blanca de Portugal a la villa. El condominio se mantuvo hasta el matrimonio de Constanza con el infante Pedro, después Pedro I de Portugal, en $1340^{36}$.

El heredero universal de los señoríos de don Juan Manuel según su testamento del 14 de agosto de 1340 debía de ser su hijo Fernando Manuel que quedaba obligado a pagar 800.000 maravedíes a su hermana Constanza en dote. Cifuentes y Val de San García además de Palazuelos, Galve de Sorbe y otras villas en La Mancha y Murcia quedarán para doña Constanza hasta el día de su boda en prenda de esos 800.000 maravedíes ${ }^{37}$. Esta cláusula ratificaba un documento anterior que recoge Layna del 6 de abril de 1339 con el mismo contenido ${ }^{38}$. Constanza Manuel se casó poco después de redactarse este testamento en el mismo 1340 y murió hacia 1345 aún en vida de su

[vieren] cómo yo Sancha Peres, muger de Diego Gomes de [borrado], e yo Toda Peres, [muger de] Gil Garcia i...? e yo Mayor Dies, hermana de las dichas Sancha Peres e Toda Peres, fijas de Gil Peres e de Francisca Peres, fiia de don Pero Garcia de Trillo, con consentimiento e con otorgamiento del dicho Diego Gomes, marido de mi la dicha Sancha Peres, e del dicho Gil Garcia, marido de mí la dicha Toda Peres, seyendo presentes, otorgamos e venimos conosçudas, de miestras buenas voluntades, sin entredicho e sin premia de ome del mundo, que vendemos a uos don Iohán, fiio del infante don [Manuel] todo el derecho que nos auyamos o deuyemos auer en Trillo con su fortalesa e [borrado] casas, solares poblados e por poblar, molinos e montes, tierras e prados e [borrado] fuentes e rrios, con aguas corrientes e non conrrientes, con entradas e con [salidas e] con todas sus pertenençias quantas ha e deue auer asi como más e meior lo auýa la [dicha] Françisca Peres nuestra madre e lo ella vendió en su vida a uos el dicho don Iohán, e nos las dichas Sancha Peres, Toda Peres e Mayor Dias lo auiamos de heredar. La qual vendida sobredicha nos otorgamos e la auemos por firme para en todo tienpo del mundo asi como la dicha Françisca Peres nuestra madre uos lo vendió en su vida. Et todo esto que sobredicho es uos vendemos a uos el dicho don Iohán la muestra parte con todo el derecho que nos en ello auemos o deue[mos] auer segunt que dicho es, por veynte mill marauedis de la moneda que fasen dies dineros el marauedi, los quales marauedis sobredichos nos otorgamos que rrecibiemos e fiuemos e somos muy bien pagadas» (Archivo Municipal de Cifuentes, pergaminos, documento 52). Esto concuerda perfectamente con la noticia del Cronicón de don Juan Manuel según la cual el hijo del infante Manuel comenzó a construir el castillo de Trillo en abril de 1322: «Era MCCCLX incepit dominus Joannes castellum de Trillo, in aprili» (FLÓREZ, Enrique (1908 [1754; segunda edición]): España Sagrada. Theatro geográphico-histórico de la Iglesia de España. Origen, divisiones y limites de todas sus provincias. Antigüedad, traslaciones y estado antiguo y presente de sus sillas, con varias dissertaciones criticas II, página 219). Desde antes de esa fecha era pues señor de este lugar don Juan Manuel, quizá en condominio con Sancha, Mayor y Toda hasta 1325 como apunta Layna (LAYNA SERrano, Francisco (1955): Historia de la villa condal de Cifuentes (Guadalajara), página 61).

36. Layna Serrano, Francisco (1994 [1933]): Castillos de Guadalajara, páginas 304 y 305 y (1955): Historia de la villa condal de Cifuentes (Guadalajara), página 65.

37. De la transcripción del testamento en GIMÉNEZ SOLER, Andrés (1932): Don Juan Manuel. Biografía y estudio crítico, páginas 696 y 697.

38. Layna SerRano, Francisco (1955): Historia de la villa condal de Cifuentes (Guadalajara), páginas 66 y 67. Dice 1329 por errata pues del contexto se deduce claramente que se trata de 1339. 
padre. Por ello cuando a fines de 1348 o principios de 1349 muere don Juan Manuel, su hijo Fernando Manuel heredó el señorío de Cifuentes sin ninguna servidumbre ${ }^{39}$. No le duró mucho pues murió, probablemente tísico como su hermana, en 1350; su hija, la niña Blanca Manuel, le sobrevivió sólo hasta $1360^{40}$. La única descendiente que quedaba de don Juan Manuel era su hija Juana Manuel ${ }^{4 !}$, casada desde 1350 con el luego rey Enrique II, pero Pedro I incorporó a la Corona sus señoríos ${ }^{42}$.

El 20 de febrero de 1367, fecha que precisa Juan Catalina García tras consultar una copia de la donación en el Archivo de Cifuentes ${ }^{43}$, el futuro Enrique II hacía uso de los señoríos de su mujer para dárselos a Alfonso de Aragón, conde de Denia, nieto de Jaime II y pretendiente muchos años después, al final de su vida, a la Corona de Aragón en Caspe, quien se convirtió en señor entre otros lugares de Cifuentes y Palazuelos. Así lo recoge Pero López de Ayala: «e dio a don Alfonso, conde de Denia, del regno de Aragón, que venía con él, la tierra que fuera de don Juan, fijo del infante don Manuel, magüer pertenecia a la reyna doña Juana, su muger del dicho rey don Enrique, que era fija legitima del dicho don [Juan] Manuel $^{44}$, e mandó que le llamasen marqués de Villena $\rangle^{4}{ }^{4}$. Esta donación fue protestada en las Cortes de Guadalajara de 1390 ante Juan I porque Enrique de Aragón, nieto y sucesor de don Alfonso, no respetaba la supremacía de la Justicia que correspondía al rey de Castilla en los lugares de señorío. Copio aquí completo el texto de la Crónica de Juan I relativo a este punto por su gran importancia para el estudio de los señoríos jurisdiccionales: «otrosí en estas Cortes fue querellado al rey por los procuradores de las cibdades e villas del regno, que el rey don Pedro e el rey don Enrique e él e algunos otros reyes sus antecesores, dieron algunas villas e donadíos a algunos señores e caballeros del regno. E por cuanto en los sus privilegios se contenía que les daban los tales logares con mero mixto imperio, los

39. Luis Rubio García sitúa en esas fechas la muerte de don Juan Manuel en su artículo (1982): «La fecha de la muerte de don Juan Manuels en Don Juan Manuel. VII centenario, página 334.

40. Layna Serrano, Francisco (1955): Historia de la villa condal de Cifuentes (Guadalajara), página 76.

41. MIGNOT, Caroline (1986): «Evolución de la estructura jurisdiccional en la región alcarreña (siglos XIXV)》 en Hispania XLVI, 163, página 255.

42. Layna Serrano, Francisco (1955): Historia de la villa condal de Cifuentes (Guadalajara), página 77 y HERrera CASADO, Antonio (1988 [1983]): Crónica y guia de la provincia de Guadalajara, página 176 y (2000): Guía de campo de los castillos de Guadalajara, página 143.

43. En Ios aumentos a la relación de Cifuentes que escribió Juan Catalina García en OrTiz García, Antonio (2002): Relaciones topográficas de la provincia de Guadalajara, edición digital.

44. La edición de la Crónica de Pedro I de la Biblioteca de Autores Españoles dice que Juana Manuel era hija del infante Manuel y no de don Juan Manuel, errata corregida en la versión de Constance Lee Wilkins y Heanon Monroe Wilkins (página 150).

45. Crónica de Pedro I en Crónicas de los reyes de Castilla (edición de Ia BAE) I, página 541. Referencias en LAyna Serrano, Francisco (1994 [1933]): Castillos de Guadalajara, páginas 308 y 309 y (1955): Historia de la villa condal de Cifuentes (Guadalajara), página 78; MIGNOT, Caroline (1986): «Evolución de la estructura jurisdiccional en la región alcarreña (siglos XI-XV)» en Hispania XLVI, 163, página 255; Herrera CASADO, Antonio (1988 [1983]): Crónica y guia de la provincia de Guadalajara, página 176 y RIESCO DE ITURRI, María Begoña (1996): Nobleza y señorios en la Castilla centro-oriental en la Baja Edad Media (siglos XIV y XV), página 1004. 
señores e caballeros que tenían las dichas villas e logares non querian responder de ningund conoscimiento de señorio al rey, por la qual cosa el su señorio soberano que avía sobre todo, se perdía o se enagenaba. E la razón porque fue esta querella dada al rey en estas Cortes, fue por quanto el rey don Enrique, su padre, dio la tierra que dicen de don Juan, que es el castillo de Garcí Muñoz e la tierra de Alarcón e el señorio de Villena e la villa de Chinchilla e Escalona e Cifuentes e otros muchos logares a don Alfonso, conde de Denia, natural del regno de Aragón, por servicio que le ficiera. E lo fizo dende llamar marqués. E después que el señorio del marquesado ovo el dicho marqués, non consentía que ninguna apelación de su tierra fuese al rey nin a la su Audiencia, nin consentia que carta del rey fuese en su tierra complida. E por tales cosas como éstas acaesce que algunas veces se pierde el señorío real; e non paran mientes los que tal cosa como ésta facen, que caen en mal caso e pierden la gracia e merced del donadio que les fue fecho. E por ende plogo al rey que esta petición fuese puesta por todos los del regno en estas Cortes e lo mandó así. E el Rey declaró esto en esta manera: "que todos los pleytos de los señorios se librasen ante los alcaldes ordinarios de la villa o lugar que era donadio de señor o caballero fasta que diesen sentencia; e si la parte se sintiese agraviada, apelase al señor de la tal villa e logar; e si el señor non le ficiese Derecho o le agraviase, estonce pudiese apelar ante el rey». E fincó asi sosegado» ${ }^{46}$.

Poco disfrutó por entonces Alfonso de Aragón de esta merced pues en abril de 1367 fue preso en el campo de batalla de Nájera por el Príncipe Negro y el rescate lo pagó en gran parte Enrique II ${ }^{47}$. Volvió después con el nuevo rey y los mercenarios franceses y fue señor de Palazuelos y de Cifuentes. En 1393, en fechas próximas a la declaración de la mayoría de edad de Enrique III, y a pesar de que Alfonso de Aragón viviría aún hasta 1412, Cifuentes pasa a su nieto, el nigromante Enrique de Aragón, cuyo padre Pedro de Aragón había muerto en 1385 en Aljubarrota y cuya madre Juana era una bastarda de Enrique II en Elvira Iñíguez ${ }^{48}$. Don Enrique, enemistado frecuentemente con Juan I y teniendo muchos de sus señoríos embargados, casó con la rica María de Albornoz, dueña del Infantado, pero en 1404 se separó de ella para ocupar el maestrazgo de Calatrava, lo que ocasionó un cisma en la orden hasta que fue depuesto en 1414: «pretendiendo el conde don Enrique su marido ser maestre de Calatrana por muerte del maestre don Gonçalo Núñez de Guzmán, que falleció en el año de 1404, se ubo de hazer diuorcio de este matrimonio con voluntad disimulada de ambas partes alegando él a ella defeto de impotencia por carecer de hijos y la condesa se recogió en el monesterio de Santa Clara de Guadalajara por mano del maestro fray Juan

46. Crónica de Juan I en Crónicas de los reyes de Castilla (edición de la BAE) II, página 141.

47. Layna Serrano, Francisco (1955): Historia de la villa condal de Cifuentes (Guadalajara), páginas 7879 (donde dice que logró huir a uña de caballo y refugiarse en Francia) y 83 (aquí cuenta lo del Príncipe Negro).

48. LAYNA SERRANO, Francisco (1955): Historia de la villa condal de Cifuentes (Guadalajara), página 85 y HERRERA CASADO, Antonio (1988 [1983]): Crónica y guía de la provincia de Guadalajara, página 176. 
Enríquez por esperança que el marido le dio que, alcançando el maestrazgo, abria dispensación del papa para boluer al matrimonio. Para lo qual el conde, renunciando en fauor del rey lo de Cangas y Tineo porque no lo heredase la orden, y haziendo lo mismo del derecho que pretendia al estado de Villena, le hizo eligir [el rey] en esta ocasión por maestre de Calatraua dos vezes, la primera en Toledo y la segunda en el convento de Calatraua donde algunos caualleros y religiosos auian elegido antes por maestre a don Luis Gonçález de Guzmán, comendador mayor de la misma orden, progenitor de los condes de Teba y marqueses de Hardales, el qual por ahora no tubo el maestrazgo sino don Enrique de Aragón por el gran fauor que le hazía el rey don Enrique. Pero continuando el pleyto entre el maestre don Enrique de Aragón y el comendador mayor, como reynando ia su hijo el rey don Juan el $2^{\circ}$ en sus tutorías, careciese el maestre del fauor pasado, vino el comendador mayor a ser maestre en al año de 1414 por última sentencia después de muchos pleytos y perdió esta gran dignidad el maestre don Enrique ${ }^{49}$. Poco después de perder el maestrazgo renunciaría al señorío de Cifuentes ${ }^{50}$ en favor de su madre Juana, casada en segundas nupcias con Dionís, hijo de Pedro I de Portugal y doña Inés de Castro ${ }^{51}$. Caroline Mignot omite a Enrique de Aragón en la lista de señores de Cifuentes al hacer heredera de don Alfonso directamente a su nuera Juana, a la que titula reina: «Alfonso de Aragón sigue poseyendo la villa en 1375, ya que en esa fecha otorga en Cifuentes un juro de 2000 maravedies anuales al monasterio de San Blas. El señorio pasa posteriormente a la reina doña Juana - esposa del infante de Portugal y madre de Enrique de Villena-quien lo usufructuó hasta 1424, fecha en que aparece bajo jurisdicción real $\rangle^{52}$. Doña Juana nunca fue reina de Portugal porque a Pedro I le sucedió su hijo legítimo Fernando I, nieto de don Juan Manuel, pero de ella nos dice Layna «que con fatuidad muy femenina haciase llamar reina de Portugal como esposa del infante don Dionis, desairado pretendiente a la Corona lusitana» y explica que Juana fue dueña de Cifuentes sólo de forma nominal hasta su muerte a finales de 1423 o en los primeros días de 1424 cuando este señorío se reincorporó a la Corona ${ }^{53}$.

\section{JUAN DE SILVA, PRIMER CONDE DE CIFUENTES (1431-1464)}

A partir de entonces la Historia de Cifuentes quedará ligada a la familia Silva, favorecida por Álvaro de Luna. Para seguir su evolución, además de los documentos procedentes del fondo Osuna y de la colección Salazar y Castro, aparte de la bibliografía, he contado con el pormenorizado inventario del archivo del conde de Cifuentes

49. RAH, Salazar y Castro, O-19, folio 148 .

50. LAyna Serrano, Francisco (1994 [1933]): Castillos de Guadalajara, páginas 309 y 310 y Herrera CASADO, Antonio (1988 [1983]): Crónica y guia de la provincia de Guadalajara, página 176.

51. LAYNA SERrano, Francisco (1955): Historia de la villa condal de Cifuentes (Guadalajara), página 87.

52. MIGNOT, Caroline (1986): «Evolución de la estructura jurisdiccional en la región alcarreña (siglos XIXV)»r en Hispania XLVI, 163, página 256.

53. Layna Serrano, Francisco (1955): Historia de la villa condal de Cifuentes (Guadalajara), página 89. 
que se elaboró en 1635 con motivo del pleito que le puso el duque de Pastrana sobre los señoríos acrecentados al primitivo mayorazgo cifontino ${ }^{54}$, y con el fondo Cifuentes del Archivo de la Nobleza de Toledo gracias al borrador de catálogo que allí me facilitaron aunque aún no estaba concluido. Este fondo consta sobre todo de documentación de la Edad Moderna pero tiene también algunos textos anteriores muy valiosos, en particular una copia completa de la donación de Cifuentes a Juan de Silva.

En el Libro de los linages de España de Pedro Jerónimo de Aponte se dice que «los de Silua proceden de Galicia, cuio mui antiguo solar está entre Duero y Miño, y fue señor dél don Gutierre que floreció a los 1070 años del nacimiento de Christo. [...] Pasó con el conde don Henrrique, yerno del rey don Alonso, a la conquista de Portugal $\rangle^{55}$. Baltasar Porreño en su Nobiliario del reyno de Galicia habla en parecidos términos: «el solar de esta gran Casa está en Galicia entre los rios Duero y Miño, junto a Pontebedra, y de esta ilustrísima Casa y solar proceden en Castilla los condes de Zifuentes, marqueses de Montemayor y duques de Pastrana» ${ }^{56}$.

Pero el primer miembro de la familia que hace al caso fue Juan de Silva (13991464), primer conde de Cifuentes ${ }^{57}$. De él trata Fernán Pérez de Guzmán al referirse al arzobispo de Toledo Pedro Tenorio, su tío abuelo: «don Juan de Silva, alférez, que fue al Concilio de Basilea e fue conde de Cifuentes» ${ }^{58}$. Su árbol de costados figura entre los que elaboró Luis de Salazar y Castro de todos los beneficiarios de títulos de nobleza hasta Felipe IV ${ }^{59}$.

Álvaro de Luna traspasó a Juan de Silva la tenencia de la fortaleza de Cifuentes, que le había entregado Juan II en 1427. En 1430 don Juan hizo el primer mayorazgo de los Silva con sus posesiones en Toledo ${ }^{60}$. Fue él quien recibió la merced de Cifuentes y su tierra de Juan II. Layna tanto en Castillos de Guadalajara como en Historia de la villa condal de Cifuentes habla de un privilegio rodado de confirmación fechado en Alcalá de Henares el 28 de febrero de $1436^{61}$ que probablemente sea el mismo que recoge el inventario del archivo de los condes de Cifuentes de 1635 con el número 27 :

54. AHN, Nobleza, Osuna, legajo 2058, expediente 1, documentos 1 y 2.

55. RAH, Pellicer, tomo XXIX, folio 408.

56. PORREÑO, Baltasar (1997 [1578]): Nobiliario del reyno de Galicia, páginas 349 y 350 .

57. Hay unas breves biografías sobre algunos de sus antepasados en RIESCO DE ITURRI, María Begoña (1996): Nobleza y señorios en la Castilla centro-oriental en la Baja Edad Media (siglos XIV y XV), páginas 79 a 83 .

58. Generaciones, semblanzas e obras de los excelentes reyes de España don Enrique el tercero e don Juan el segundo y de los venerables perlados y notables caballeros que en los tiempos destos reyes fueron de Fernando Pérez de Guzmán en Crónicas de los reyes de Castilla (edición de la BAE) II, páginas 705 y 706.

59. RAH, Salazar y Castro, D-21, folio 43.

60. AHN, Nobleza, Osuna, legajo 2501, expediente 10, documento 1, folios 1 a 2 vuelto. Los documentos 1 y 2 de este expediente son dos impresos iguales que copian los llamados seis mayorazgos del condado de Cifuentes a pesar de que el primero aún no incluyera patrimonio alguno en la Alcarria; constituyen la forma más eficaz de seguir las sucesivas ampliaciones del señorío de los Silva.

61. Layna Serrano, Francisco (1994 [1933]): Castillos de Guadalajara, páginas 311 y 312 y (1955): Historia de la villa condal de Cifuentes (Guadalajara), página 90. 
«merced y preuilexio rodado de el señor rey don Juan en que haze merced y confirma la que tenia hecha a Juan de Silua de la villa de Cifuentes con sus términos y juridiçión, vassallos y rrentas. Firmado de el dicho rey y sellado con un sello de plomo pendiente en filos de sseda de colores y las armas de Castilla y León iluminadas. $Y$ está rrefrendado de Fernando Díaz de Toledo, oydor y rrefrendario del rey. Dado en la villa de Alcalá de Henares en [veinte e] ocho días de febrero del año de mill e quatroçientos e treinta y seis. Está escrito en un pergamino entero grande, a lo ancho, que queda firmado a las espaldas de mi, el pressente scriuano de cámara $\rangle^{62}$. Herrera Casado se refiere a la entrega de la tenencia del castillo por Álvaro de Luna a Juan de Silva para luego añadir únicamente «este gentil hombre es nombrado por el monarca Juan II primer conde de Cifuentes. En esta familia seguiria la villa y su amplio alfoz, progresivamente ampliado por compras y trueques, hasta la abolición de los señorios en $1812>\rangle^{63}$. María Begoña Riesco de Iturri, la investigadora que más ha estudiado el señorio de Cifuentes, se basa en la Historia genealógica de la Casa de Silva de Salazar y Castro para afirmar que esta merced se produjo en 1430; lo dice en un artículo de 1992 y en su posterior tesis doctoral de $1996^{64}$.

La confirmación de 1436 que Layna debió conocer sólo por referencias ya que no da la fecha de la merced primitiva de Juan II, se encuentra hoy en el fondo Cifuentes del Archivo de la Nobleza. La donación original inserta está «dada en la villa de Medina del Campo dies dias de marzo año del nascimiento del Nuestro Señor Jesuchristo de mil y quatrocientos y treinta y un años ${ }^{65}$, dato que ya aportó Juan Catalina García en los aumentos a la relación de Cífuentes sin citar en qué se había basado ${ }^{66}$. El meollo del documento dice: «don Johán, por la gracia de Dios rey de Castilla, de León, de Toledo, de Galicia, de Sevilla, de Córdova, de Murcia, de Jahén, del Algarve, de Algesira y señor de Viscaya y de Molina, por facer bien y merced a don Johán de Silva, mi criado y mi notario mayor del regno de Toledo, por muchos y buenos y leales servicios que que (sic) el adelantado Alfón Tenorio, vuestro padre, y los otros onde vos venides ficieron al rey don Enrrique, mi padre y mi señor, que Dios dé Santo Paraíso, e a los otros reys de gloriosa memoria mis progenitores y a mí, y vos me avedes fecho y facedes de cada dia, y en emienda y remuneración dellos, otrosí por quanto yo seguré y prometí al dicho adelantado, vuestro padre, al tiempo que era vivo, de le heredar y hacer merced de vasallos, fago vos merced y gracia y donación pura y propia y non revocable, para

62. AHN, Nobleza, Osuna, legajo 2058, expediente 1, documento 1, número 27.

63. Herrera CASAdo, Antonio (1988 [1983]): Crónica y guia de la provincia de Guadalajara, página 176 y (2000): Guia de campo de los castillos de Guadalajara, página 144.

64. RIESCO DE ITURRI, María Begoña (1992): «Constitución y organización de un señorío nobiliario en el obispado de Sigüenza a finales de la Edad Media: el condado de Cifuentes» en Wad-al-Hayara 19, página 213 y (1996): Nobleza y señoríos en la Castilla centro-oriental en la Baja Edad Media (siglos $X I V$ y $X V)$, página 1005.

65. AHN, Nobleza, Cifuentes, caja 2, documento 15, folio 2 vuelto.

66. En Ortiz Garcia, Antonio (2002): Relaciones topográficas de la provincia de Guadalajara, edición digital. 
vos y para vuestros herederos y subscesores, por juro de heredat para siempre jamás, de la mi villa de Cifuentes y su tierra con su castillo y fortaleza y con su término y distrito y Justicia y juridición cevil y criminal y mero mixto imperio y penas y calupnias $y$ rentas y pechos $y$ derechos y otras qualesquier cosas pertenescientes al señorío real de la dicha villa y su tierra y con todas las otras sus pertenencias $)^{67}$. Se trata por tanto de una merced plenamente jurisdiccional típica de la época y en la que, gracias al favor de Álvaro de Luna, no falta ninguna concesión; el monarca sólo se reserva las regalías habituales («e que queden ende siempre para mí y para la Corona real de mis regnos, para siempre jamás, alcavalas y tercias y otrosí pedido y monedas cuando los otros lugares de los mis regnos me los ovieren de pagar, y mineros de oro y plata y otros qualesquier metales y la maioría de la Justicia y todas las otras cosas que pertenescen al señorio real y se non pueden apartar dél $\rangle^{68}$ ), entre las que figura también, como vemos, la supremacía de la Justicia que había motivado la protesta de las Cortes de Guadalajara en 1390 contra los abusos de Alfonso de Aragón.

En 1441 Juan de Silva empezó a incrementar sus señoríos atencinos al comprar Huetos y Ruguilla al monasterio de Ovila. Riesco de Iturri para estudiar esta operación utilizó el inventario del Archivo de Cifuentes del legajo 2058 de Osuna, donde se registra «la venta quel abad y frayles de el monasterio de Ochila (sic) hiçieron de los lugares de Güetos y Rruguilla en fabor de don Juan de Ssilua por ssiete mill marabedis de juros perpetuos sobre las alcabalas de Biruega (sic). Su fecha en el dicho monasterio en quince dias del mes de otubre de mill y quatrocientos e quarenta y un años ante Juan Gonçález de Alcoçer, escriuano real. Escripto en un pergamino grande»" ${ }^{69}$. En su artículo de 1992 sobre el condado de Cifuentes dice que Huetos y Ruguilla «los compró don Juan de Silva I al abad y monjes del monasterio de Ovila por 7000 maravedies $\rangle:$ la documentación en cambio señala que fue por 7000 maravedíes de juro anual sobre las alcabalas de Brihuega «pagados en tres terzios por mayo, septiembre $y$ Nabidad ${ }^{70}$, lo que se ajusta más a la realidad de los precios. En el fondo Cifuentes del Archivo Histórico Nacional se conserva un testimonio notarial sacado en $1702 \mathrm{del}$ «privilegio que el rey don Juan segundo hizo en (espacio en blanco) de (espacio en blanco) de (espacio en blanco) a don Juan de Silva, su alférez mayor, y a don Alfonso de Silva, su hijo, para que los 10.000 maravedis que tenian por merced en cada un año por juro de heredad, los pudiesen remunciar, dar y traspasar o mandar o enagenar o cambiar o permutar, en cualquiera tiempo y en cualquiera yglesia o monasterio, orden o religión, etcétera, situados por pribilegio señaladamente en cualquiera rentas o de las alcabalas de cualquiera ciudad o villa, en virtud de cuya concesión permutó siete

67. AHN, Nobleza, Cifuentes, caja 2, documento 15, folio 1 vuelto.

68. AHN, Nobleza, Cifuentes, caja 2, documento 15, folio 2.

69. AHN, Nobleza, Osuna, legajo 2058, expediente 1, documento 1, número 203. RIESCO DE ITURRI, María Begoña (1992): «Constitución y organización de un señorío nobiliario en el obispado de Sigüenza a finales de la Edad Media: el condado de Cifuentes») en Wad-al-Hayara 19, página 214 y (1996): Nobleza y señorios en la Castilla centro-oriental en la Baja Edad Media (siglos XIV y XV), páginas 204 y 1073.

70. AHN, Nobleza, Cifuentes, caja 2, documento 5, folio 1. 
mil maravedis de dicha cantidad que tenia situada sobre las alcabalas de Brihuega con el monasterio de Santa María de Orbila (sic) del orden de San Bernardo, por la jurisdicción y señorio de los lugares de Ruguilla y Güetos»y. Juan de Frías, el escribano que debía dar el testimonio, fue a Ovila «y en un libro anttiguo de dicho monasterio ynttitulado Tumbo del monasterio, al folio 31 , alle una anottazión del thenor siguiente: «Brigüega. Tiene este monasterio, de juro perpettuo, en la villa de Brigüega, sobre las alcaualas de dicha villa, siette mill maravedís pagados en tres terzios por mayo, septiembre y Nabidad. Trocolos el conde de Zifuenttes por la jurisdizión y señorío que estte monastterio ttenía en los lugares de Güetos y Ruguilla según pareze por una escriptura que ay en el arca de la comunidad»»». Copia después un documento en el que Alfonso, primogénito de Juan de Silva y tras su muerte segundo conde de Cifuentes, ratifica la cesión de los 7000 maravedíes de renta al monasterio, cuya fecha dice: «otorgada en el castillo de la villa de Cifuenttes a ocho dias del mes de abrill año de el nacimientto de Nuestro Señor Jesuchristo de mill y quatrocientos y quarentta $y$ dos años $\rangle^{71}$. Parece por tanto que Juan de Silva y los monjes de Ovila firmaron el trueque el 15 de octubre de 1441 pero que hasta el 8 de abril del siguiente año su hijo Alfonso, destinatario como su padre de la merced real de 10.000 maravedíes con parte de los cuales se pagaron Huetos y Ruguilla, no confirmó la renta que debía recibir el monasterio. Layna Serrano en Castillos de Guadalajara se refiere varias veces a las ventas que hizo Alfonso Carrillo de Acuña a Juan de Silva, tercer conde de Cifuentes, en 1475 y 1478; en una de ellas mete incomprensiblemente a Ruguilla, que nunca fue de don Alfonso, al afirmar que «andaban los condes de Cifuentes ensanchando su patrimonio a costa de caballeros manirrotos (habian comprado Gárgoles, Sotoca y Ruguilla a Alfonso Carrillo; Torrecuadrada a don Juan de la Cerda, hijo del III conde de Medinaceli) \> ${ }^{72}$. Además ya desde 1458 Huetos y Ruguilla formaban parte del segundo mayorazgo de los Silva, que incluía estos bienes: «la mi villa de Cifuentes, que es en el obispado de Sigüença, con su castillo y fortaleza y vassallos y casas y heredades $y$ con todas sus aldeas y con las otras aldeas de Huettos y Ruguilla que después yo oue comprado ý en troque y en cambio del abad y monges de Santa Maria de Ouila, con la juridición ciuil y criminal, alta y baxa y mero mixto imperio de la dicha villa e logares $y$ con todos sus términos $y$ rentas, pechos $y$ derechos $y$ tierrass ${ }^{73}$.

El 25 de septiembre de 1444 Juan de Silva es apoderado por el príncipe de Asturias junto a Alfonso Álvarez de Toledo para la permuta de Carrión de los Condes, villa propia del futuro Enrique IV, por 1500 vasallos en el Real de Manzanares que habrá de entregar Îñigo López de Mendoza, desde el año siguiente primer marqués de Santillana ${ }^{74}$, una de las operaciones patrimoniales más importantes de la época, lo que demuestra que el señor de Cifuentes seguía figurando entre los personajes principales

71. AHN, Nobleza, Cifuentes, caja 2, documento 5.

72. Layna Serrano, Francisco (1994 [1933]): Castillos de Guadalajara, páginas 370 y 371.

73. AHN, Nobleza, Osuna, legajo 2501, expediente 10, documento 1, folio 7.

74. RAH, Salazar y Castro, M-25, folios 140 y 140 vuelto. 
del reino. Del 23 de febrero de 1456 se conserva un documento por el que recibe oficialmente el título de conde de Cifuentes: «considerada la persona e estado e linage de vos, Juan de Silva, del mi Consejo, que fasta aqui érades mi alférez maior del mi pendón real, y los muchos y buenos e leales servicios que aquellos donde vos venides fecieron a los reyes de gloriosa memoria mis progenitores y vos habedes fecho y facedes a mi de cada día y espero que faredes de aqui adelante, queriendo honrar, sublimar vuestra persona y por vos facer bien y merced, tengo por bien y es mi merced que agora e de aquí adelante para en toda vuestra vida seades conde de la vuestra villa de Cifuentes e do vos por la presente el titulo y nombre e dignidad de conde y vos envisto en él y quiero e es mi merced y voluntad que de aqui adelante vos podades llamar y nombrar don Juan de Silva, conde de Cifuentes, e que los que de vos decendieren y obieren y heredaren la dicha villa aiades e seades nombrados e llamados por el dicho nombre y que aiades y gocedes y vos sean guardadas todas las honras e gracias y franquezas e esenciones e preheminencias y prerrogativas e inmunidades e todas las otras cosas y cada una dellas que son y deben ser guardadas e de que deben aver e gozar los otros condes de mis regnos $\rangle^{75}$. Riesco de Iturri considera que pudo ejercer como tal desde abril o mayo de $1455^{76}$, lo que concuerda con la opinión de Salazar y Castro en sus Árboles de costados de los titulos que an concedido nuestros reies hasta Phelipe IV el Grande, donde dice esto del título de conde de Cifuentes: «Enrique 4. Año 1455 y el $1^{\circ}$ de los suioss ${ }^{77}$.

Tras recibir todas estas mercedes Juan de Silva decidió ordenar la herencia de sus hijos y por eso el 15 de agosto de 1458 dio dos nuevos mayorazgos y otorgó testamento. Alfonso de Silva, primogénito de su primera mujer Leonor de Acuña ${ }^{78}$, recibía «la mi villa de Cifuentes, que es en el obispado de Sigüença, con su castillo y fortaleza y vassallos y casas y heredades y con todas sus aldeas y con las otras aldeas de Huettos y Ruguilla que después yo oue comprado ý en troque y en cambio del abad y monges de Santa María de Ouila, con la juridición ciuil y criminal, alta y baxa y mero mixto imperio de la dicha villa e logares y con todos sus términos y rentas, pechos y derechos y tierras, según que mejor y más cumplidamente el dicho señor rey don Iuan de la dicha villa y su tierra me fizo merced, y seguin lo que yo tengo y posseo y pertenece $y$ pertenecer deue assi por merced del dicho señor rey como por el dicho troque $y$ cambio, y con mi lugar de Fuentepinilla, que es cerca de la dicha villa de Cifuentes, con todas sus rentas y derechos y montes y términos y prados y aguas corrientes $y$ manantiales, según que lo yo tengo y posseo y me pertenece y pertenecer deue en

75. RAH, Salazar y Castro, M-94, folios 263 vuelto y 264.

76. RIESCO DE ITURRI, María Begoña (1996): Nobleza y señoríos en la Castilla centro-oriental en la Baja Edad Media (siglos XIV y XV), página 221.

77. RAH, Salazar y Castro, D-21, folio 43.

78. Era hija de Teresa Carrillo y Lope Vázquez de Acuña, hermana de Alfonso Carrillo de Acuña (obispo de Sigüenza, arzobispo de Toledo y señor de Alcorlo y los sexmos del Bornova y el Henares) y de Gómez Carrillo de Acuña (señor de Jadraque y la tierra de Mandayona) y sobrina del cardenal Alonso Carrillo de Albornoz, señor de Ocentejo. 
qualquier manera y por qualquier razón» ${ }^{79}$. Su hermanastro Juan de Ribera, hijo de Inés de Ribera, segunda mujer de Juan de Silva, fue heredado en Montemayor del Río, hoy provincia de Salamanca ${ }^{80}$. El testamento ratifica ambos vínculos y ordena a su hijo Juan que deje el apellido Silva y tome el Ribera de su madre porque así lo exigen los mayorazgos que va a heredar de sus antepasados: «quiero y es mi voluntad quel dicho don Johán de Rivera, mi fijo, y sus decendientes aya el dicho maioradgo que yo así a él fice no embargante quél non tenga mi apellido de mi linage de Silva nin traiga mis armas, por quanto al dicho don Johán de Rivera, mi fijo, y sus decendientes pertenecen los maioradgos que fueron fechos y constituidos por el adelantado Pero Afán de Rivera el Viego, su visagüelo, e por el adelantado don Diego Gómez de Rivera, su ahuelo, o qualquier dellos, y segund las condiciones de los dichos mayoradgos él ha de traher el apellido y armas de Rivera $\rangle^{81}$.

Los bienes que recibe Alfonso de Silva en el concejo de Atienza son pues Cifuentes y su tierra, Huetos, Ruguilla y Fuentepinilla. El problema está en saber qué es la tierra de Cifuentes. Incluye sin duda la aldea de Val de San García que citan los documentos de la época de don Juan Manuel y que si deja de nombrarse ahora debe ser por su escasa importancia y cercanía a la capital. Más difícil es saber qué ocurría con Valderrebollo, lugar que el manuscrito de la Renta del Tabaco de 1752 atribuye a los condes de Cifuentes ${ }^{82}$ pero del que no conozco ningún documento en que conste expresamente su entrada en esta Casa. Riesco de Iturri apoyándose en la Historia genealógica de la Casa de Silva cree que se incluyó en la donación de Cifuentes a Juan de Silva ${ }^{83}$ pero allí sólo dice «Cifuentes y su tierra». Es el testamento de 1504 de Juan de Silva, tercer conde de Cifuentes, el texto que confirma la pertenencia de este lugar a las «aldeas antiguas» de Cifuentes: «mando que don Fernando de Silua, mi hijo mayor, demás de mis mayorazgos antiguos, que son la villa de Barcience y la mitad del mi lugar de Ciruelos y Vililla y Torrezilla y los molinos de Vergoña y la villa de Cifuentes con sus aldeas antiguas, que son Trillo y Valderebollo, el Valde (sic) de San García y más Huetos y Ruguilla y Fuentepinilla, que el conde don Iuan de Silua

79. AHN, Nobleza, Osuna, legajo 2501, expediente 10, documento 1 , folios 7 y 7 vuelto.

80. AHN, Nobleza, Osuna, legajo 2501, expediente 10, documento 1, folio 13. La descendencia de Juan de Ribera figura en RAH, Salazar y Castro, D-21, folio 259 y en LÓPEZ DE HARO, Alonso (1996 [1622]): Nobiliario genealógico de los reyes y títulos de España II, páginas 380 y 381 ; su retataranieto Juan de Silva y Ribera, quinto marqués de Montemayor del Río, pretenderá el condado de Cifuentes en 1644 como veremos más adelante.

81. RAH, Salazar y Castro, M-94, folios 47 a 54 vuelto.

82. LOINAZ, Martín de (1752): Noticias yndividuales de los pueblos que se componen los reynos, provincias y partidos de esta penínzula de España bajo el govierno de la renta del tavaco, los que pertenecen al rey, a señorio, a abadengo y a mixto (se conserva en la Biblioteca Provincial de Toledo, fondo Lorenzana, manuscrito 529; yo he manejado una fotocopia que me proporcionó la profesora María Luisa de Villalobos y Martínez-Pontrémuli), provincia de Guadalajara, pueblo 517.

83. Riesco DE ITURRI, María Begoña (1992): «Constitución y organización de un señorío nobiliario en el obispado de Sigüenza a finales de la Edad Media: el condado de Cifuentes» en Wad-al-Hayara 19, página 213. 
mi señor abuelo metió en el mayorazgo, e la tercia parte de las casas principales que yo tengo en la ciudad de Toledo, que demás de lo susodicho aya y le queda la mi villa de Escamilla con su fortaleza». Fuentepinilla aparece en la donación de la tierra de Mandayona a María de Castilla y Gómez Carrillo de Acuña en $1434^{84}$. Juan de Silva, primer conde de Cifuentes ${ }^{85}$, en el mayorazgo de 1458 afirma su posesión claramente aunque no explica el derecho de propiedad como sí lo hace al referirse a Huetos y Ruguilla («que después yo oue comprado ý en troque y en cambio del abady monges de Santa María de Ouila»): «según que lo yo tengo y posseo y me pertenece y

84. AHN, Nobleza, Osuna, legajo 2045, expediente 1, documentos 1 a 10 y RAH, Salazar y Castro, M-4, folios 74 vuelto a 76. LAYNA SERRANo, Francisco (1945): Historia de la villa de Atienza, páginas 174 y 175 y (1955): Historia de la villa condal de Cifuentes (Guadalajara), páginas 93 y 94; MARTíNEZ DíEZ, Gonzalo (1983): Las comunidades de villa y tierra de la extremadura castellana (estudio históricogeográfico), páginas 269 y 271; FRANCO SILVA, Alfonso (1996; artículo de 1983): La fortuna y el poder. Estudios sobre las bases económicas de la aristocracia castellana (siglos XIV-XV), página 317; CuENCA, Emilio y Olmo, Margarita del (1984): El Cid Campeador y Gómez Carrillo de Acuña. Dos personajes para Jadraque, páginas 46 a 48; HERRERA CASADO, Antonio (1989): Castillos y fortalezas de CastillaLa Mancha, página 175; FerNÁNDEZ MADrid, Maria Teresa y Gómez LORENTE, Manuel (1992): «Los bienes del marqués de Cenete en la provincia de Guadalajara (1492-1523)» en Wad-al-Hayara 19, páginas 236 y 237; RIESCO DE ITURRI, María Begoña (1996): Nobleza y señoríos en la Castilla centro-oriental en la Baja Edad Media (siglos XIV y XV), páginas 91 y 1031 y DAZA PARDO, Enrique (2001): «El castillo del Cid (Jadraque)» en Castillos de España 120 (enero), página 53.

85. Pedro Jerónimo de Aponte copia el curioso epitafio del primer conde de Cifuentes bajo el que está sepultado en la iglesia de San Pedro Mártir de Toledo: «aqui reposa el mui noble y mui magnifico señor don Juan de Silua, conde de Cifuentes, señor de Montemaior, alférez del pendón del rey, animoso y singular y mui famoso varón en todos actos de caualleria $y$, por merecimiento de su prudencia y discreción, el glorioso rey don Juan le dio la honrra de la embajada y le ymbió al conçilio que se celebró en Vasilea, en Alemania, el qual, con grande representación e orgullosas obras, su authoridad mostrando contra la condizión a los yngleses, la silla a él quitada, e primero a nuestro rey y a su reyno por aquéllos usurpada, varonilmente la defendió e reformó e dejó por pacifica para siempre. Finó jueues a 27 de septiembre de 1464) (RAH, Pellicer, tomo XXIX, folios 410 y 410 vuelto. LóPEZ DE HARO, Alonso (1996 [1622]): Nobiliario genealógico de los reyes y títulos de España I, página 536, copia el mismo epitafio pero retrasando por error la muerte del conde hasta 1474). Hernando del Pulgar lo cuenta con más detalle: «acaesció en sus tienpos que todos los príncipes christianos se acordaron con los perlados e clerezia de fazer concilio en la ciudad de Basilea, que es en la Alta Alemania, sobre una gran cisma que por estonces avía en la yglesia de Dios entre el papa Eugenio e otro que se llamó Félix. A la qual congregación como todos acordassen embiar sus enbaxadores porque conuenia mostrarse en aquella congregación la magnificencia e poderio de los reyes, el rey don Juan, conocida la sufficiencia deste cauallero, le cometió esta enbaxada y enbió con él grandes letrados. [...] E como acaesciesse un día que el embaxador del rey de Inglaterra quisiesse anticiparse e ocupar el lugar de la precedencia que al rey de Castilla pertenescia, no pudiendo este cauallero sofrir tienpo para que se determinase por razón lo que veýa leuar por fuerça, llegó a aquel embaxador e puestas las manos en él con gran osadía le arrebató y echó de aquel lugar y él se puso en él. [...] Preguntado por el cauallero presidente de la Justicia cómo avía osado poner las manos en tan notable embaxador e de tan gran príncipe como era el rey de Inglaterra, con ánimo no vencido le respondió: «digoos, presidente, que quando padesce defecto la razón no deuen faltar manos al coraçón». E con su gran osadía junto con su buena razón fue guardada la preheminencia del rey e la honrra del reyno e fue amansado aquél escándalo» (PULGAR, Hernando del (1970 [c. 1485]): Los claros varones de Castilla, páginas 53 a 55). 
pertenecer deue en qualquier manera y por qualquier razón $\rangle^{86}$. Las posibles diferencias sobre este lugar entre Silvas y Carrillos se solucionarían definitivamente cuando el tercer conde compró en 1475 Gárgoles de Abajo, en cuyo término se encontraba Fuentepinilla, a Alfonso Carrillo de Acuña ${ }^{87}$.

\section{LOS CONDES DE CIFUENTES HASTA LOS PLEITOS DE SUCESIÓN} (1464-1606)

Alfonso de Silva (1429-1469), segundo conde de Cifuentes, casó en primeras nupcias con Isabel de Castañeda quien en 1462 en el tercer mayorazgo de Cifuentes incorporó la mitad de Palos de la Frontera ${ }^{88}$ lo que si bien dio lugar a varios pleitos se mantuvo en la Casa de Silva hasta que lo compraron los Reyes Católicos en $1492^{89}$. Tras el fallecimiento de doña Isabel don Alfonso casó con Beatriz Pacheco ${ }^{90}$, y testó el 12 de mayo de $1468^{91}$. El 30 de noviembre de ese año juró a la princesa Isabel como heredera de Castilla: «paresçió presente don Alfón de Silua, conde de Çifuentes, e dixo que por quanto la subçesión destos regnos e señorios pertenesçía a la dicha señora prinçesa después de los días del señor rey su hermano, por ende que él reconosçía e reçebía por prinçesa, por primogénita heredera de los dichos regnos a la dicha señora prinçesa doña Ysabel e por reyna dellos para después de los dias del dicho señor rey su hermano e que él la seruirá e guardará su vida e estado con toda obediençia e lealtad $\rangle^{92}$. La muerte del segundo conde de Cifuentes según la Crónica de Enrique IV de Diego Enríquez del Castillo ocurrió poco después de la concesión del título de duque de Arévalo el 28 de septiembre de 1469 a Álvaro de Estúñiga ${ }^{93}$ : «confirmada la merced de Arévalo e dado el título de duque della, el rey se partió para Guadalupe e de allí a Segovia. En aqueste medio tiempo murió el marqués de Astorga y el conde de Cifuentes e subcedieron sus hijos en los titulos e señorios» ${ }^{94}$.

86. AHN, Nobleza, Osuna, legajo 2501, expediente 10, documento 1.

87. Cuando en 1479 el conde done a Cifuentes la jurisdicción en primera instancia de los pueblos que había comprado de Alfonso Carrillo citará entre ellos a Fuentepinilla (RAH, Salazar y Castro, T-29, folio 359 vuelto).

88. AHN, Nobleza, Osuna, legajo 2501, expediente 10, documento I, folios 24 vuelto a 25 vuelto. Doña Isabel era hija de Juan Rodríguez de Castañeda (hijo de María de Orozco y Juan Rodríguez de Castañeda y nieto de Íñigo López de Orozco) y de Juana de Guzmán, señora de Palos de la Frontera e hija de Álvar Pérez de Guzmán, señor de Gibraleón y Palos de la Frontera (VÁlgoma Y DíAz-VARELA, Dalmiro de la (1959): Historia genealógica de la Casa de Haro (señores de Llodio - Mendoza-, Orozco y Ayala) de don Luis de Salazar y Castro, páginas 132 a 135).

89. LADERO QueSADA, Miguel Ángel (1973): Andalucia en el siglo XV. Estudios de Historia politica, página 15.

90. Hija bastarda de Juan Pacheco en Catalina Ludeña y viuda de Rodrigo Portocarrero, conde de Medellín.

91. RAH, Salazar y Castro, M-94, folios 84 a 92.

92. AGS, Patronato Real, Juramentos y pleito-homenajes, caja 7, documento 113.

93. AHN, Nobleza, Osuna, legajo 279, expediente 4, documento 1 b y expediente 14.

94. Crónica de Enrique IV de Diego Enríquez del Castillo en Crónicas de los reyes de Castilla (edición de la BAE) III, página 190 . 
El tercer conde de Cifuentes, llamado Juan de Silva (1452-1512) como su abuelo, fue el que más incrementó los estados de los Silva en la Alcarria: el 6 de junio de 1475 adquirió Gárgoles de Abajo, Gárgoles de Arriba y Sotoca de Tajo ${ }^{95}$ y el 17 de diciembre de 1478 Henche, Solanillos del Extremo, Olmeda del Extremo, Ureña del Campo ${ }^{96}$ y El Villar ${ }^{97}$. En un documento sin fecha pero que aparece en la colección Salazar y Castro justo después de estas dos compras, los Reyes Católicos prohíben a Juan de Silva que

95. Tanto la documentación como el historiador del legajo 3329 de Osuna sitúan claramente la venta en esa fecha: «en Toledo a 6 de junio de 1475 ante Gómez Fernández de Gómara, escriuano, Alfón Carrillo, señor de las villas de Maqueda y Mandayona, vende a don Juan de Silua, conde de Zifuentes, alférez maior del rei y del su Consejo y su alcalde maior de las alzadas de Toledo, los lugares de Gárgoles de Iuso, Gárgoles de Suso y Sotoca con todos sus vasallos, términos, jurisdiciones, pechos e derechos, etcétera por un quento de marauedis de la moneda usual» (RAH, Salazar y Castro, M-1, folio 129 vuelto); ufecha y otorgada en la dicha çibdad de Toledo seis dias del mes de junio año del nascimiento de Nuestro Saluador Jesuchristo de mill e quatroçientos y setenta y cinco años» (RAH, Salazar y Castro, M-25, folio 34); «los Gárgoles y Sotoca. Estos tres lugares, procedidos de la merced misma a doña Maria de Castilla, muger de Gómez Carrillo de Acuña, y de la subsequente al arzobispo Carrillo, los vendió Alfonso Carrillo, hijo de aquéllos y sobrino de éste, a don Juan de Silva, conde de Cifuentes, por escritura de 6 de junio de 1475 ante Gómez Fernández de Gomera, esscriuano, en Toledo por un quento de maravedis sin reserva de cosa alguna según y como le pertenecian por privilegio real» (AHN, Nobleza, Osuna, legajo 3329, expediente 1, pie 7, folio 3 vuelto). En cambio Manuel Pérez-Villamil y García en los aumentos a las Relaciones de Felipe II dice 6 de junio de 1476 (OrTIZ Garcia, Antonio (2002): Relaciones topográficas de la provincia de Guadalajara, edición digital, relación de Gárgoles de Arriba) y Riesco de Iturri 16 de junio de 1475 («Constitución y organización de un señorío nobiliario en el obispado de Sigüenza a finales de la Edad Media: el condado de Cifuentes» en Wad-al-Hayara 19, página 214, y Nobleza y señoríos en la Castilla centro-oriental en la Baja Edad Media (siglos XIV y XV), páginas 1005 y 1006).

96. Despoblado no localizado por Martínez Díez (Las comunidades de villa y tierra de la extremadura castellana (estudio histórico-geográfico), páginas 273 a 284), que debe encontrarse muy próximo a los otros lugares incluidos en la venta.

97. «Sepan quantos esta carta bieren cómo yo, Alfonso Carrillo, señor de la villa de Maqueda, de mi propia y libre y agradable y espontánea boluntad, non indusido nin traido por dolo nin fraude nin cautela alguna, antes en mi propio aluedrio y sin sobornación alguna, otorgo y conozco que bendo y por titulo de venta do y dono por juro y heredat para agora y para siempre jamás a bos, el magnifico señor don Juan de Silua, conde de Cifuentes, alférez maior del rey nuestro señor y del su Consejo, que estades absente, bien así como si fuésedes presente, los mis lugares de Enche y Solanillos, poblados y despoblados, y El Olmeda del Extremo y El Villar y Herrueña del Campo con todos sus basallos y señorio y con la jurisdición ciuil y criminal alta y baja y mero y mixto imperio y rentas y pechos y derechos e portazgos de ellos segund y de la forma y manera que los yo he y tengo y poseo» (AHN, Nobleza, Osuna, legajo 2066, expediente 2, documento 2 y RAH, Salazar y Castro, M-1, folio 129 vuelto (en el mismo folio inmediatamente después hay una noticia de la toma de posesión los días 22, 23 y 24). CUENCA, Emilio y Olmo, Margarita del (1984): El Cid Campeador y Gómez Carrillo de Acuña. Dos personajes para Jadraque, página 50 y RIESCO DE ITURRI, María Begoña (1992): «Constitución y organización de un señorío nobiliario en el obispado de Sigüenza a finales de la Edad Media: el condado de Cifuentes» en Wad-al-Hayara 19, página 214, y (1996): Nobleza y señorios en la Castilla centro-oriental en la Baja Edad Media (siglos $X I V Y X V$ ), página 1006). En el inventario del archivo de Cifuentes de 1635 la escritura de esta venta aparece en dos ocasiones (AHN, Nobleza, Osuna, legajo 2058, expediente 1, documento 1, números 24 y 89) y el legajo 3329 de Osuna la refiere asi: «Solanillos, Olmeda, Enche, El Villar y Herrueña del Campo. Estos cinco lugares, procedidos de dicha merced, los vendió el citado Alfonso 
compre pueblos de la tierra de Mandayona porque estaban hipotecados al pago de las arras de Leonor de Toledo ${ }^{98}$. Se vio entonces obligado Alfonso Carrillo a hipotecar un lugar de su señorío de Maqueda para garantizar lo adquirido por el conde de Cifuentes: «notificósele al conde don Juan una prouisión de los Reies Católicos para que no comprase lugares algunos de tierra de Mandayona porque estauan hipotecados a las arras de doña Leonor de Toledo y que le pondría pleito, por lo qual Alonso Carrillo sale nuebamente al saneamiento de la venta, haze pleito omenage de obserbarla y defenderla en manos de Luis de ¿Contreras? Martines, cauallero, ome hijodalgo, y hipoteca nuebamente su lugar de Santo Domingo9, término de Maqueda. Fecho todo en Alcalár ${ }^{100}$.

En 1479 el conde vendió a su villa de Cifuentes por 200.000 maravedíes la jurisdicción en primera instancia de los lugares de la tierra de Mandayona que había comprado de Alfonso Carrillo así como la de Huetos y Ruguilla: «sepan quantos esta carta vieren cómo yo, don Iuán de Silua, conde de Cifuentes, alférez mayor del rey nuestro señor y del su Consejo, que por fazer bien y merced a vos, el concejo, alcayde y alcaydes, alguaziles, regidores, oficiales, hombres buenos de la mi villa de Cifuentes e por acrecentar en honra y jurisdición la dicha villa por muchos cargos que de vos, el dicho concejo, tengo e seruicios que me auéis hecho y en enmienda y remuneración de aquéllos y porque aora de nueuo me seruis con ducientas mil marauedis, vos fago merced, gracia y donación para que de aqui adelante para sienpre jamás, vos, el dicho concejo, tengáys por vuestra y de la dicha villa y so el señorio della la jurisdición ciuil y criminal, alta, baxa de los mis lugares que yo huue y conpré del señor Alfonso Carrillo de Acuña, señor de la villa de Maqueda, que son: amos los Gárgoles, Sotoca y Enche y Solanillos y El Olmeda y El Villar y Erueña del Canpo y Fuentepenilla, término que fueron de la villa de Mandayona, e assí mismo de los mis lugares de Güetos $y$ Ruguilla, todo según que lo yo tengo y posseo y me pertenece en qualquier manera. Esto para que vos, el dicho concejo de la dicha mi villa, tengáis la dicha jurisdición ciuil y criminal en los dichos lugares y términos e vezinos y moradores dellos, para que esté so el señorío desta mi villa de la forma y manera que vos, el dicho concejo, tenéys y auéys tenido los mis lugares de Trillo y Balderreuollo y no para más señorio y jurisdición, tanto y con tal condición que para aora y para siempre jamás quede por mí y para los que de mí vinieren la superioridad de la dicha jurisdición de los dichos lugares y términos según que lo he tenido y tengo en los dichos lugares de Trillo y Balderreuollo ${ }^{101}{ }^{1}$. Mucho después en 1635 , el concejo de Cifuentes pondría pleito a

Carrillo al mismo don Juan de Silva el 17 de diciembre de 1478 ante (espacio en blanco) en precio de 775.000 marauedis» (AHN, Nobleza, Osuna, legajo 3329, expediente 1, pie 7, folio 3 vuelto).

98. Leonor de Toledo, tataranieta de Íñigo López de Orozco y señora de Pinto, era la mujer de Alfonso Carrillo de Acuña: «casó con doña Leonor de Toledo, señora de Pinto, hija de Pero Suárez, señor de Pinto, y de doña Juana de Guzmán» (RAH, Salazar y Castro, D-30, folio 275).

99. Es Val de Santo Domingo, pueblo hoy integrado en el municipio de Santo Domingo-Caudilla.

100. RAH, Salazar y Castro, M-1, folio 129 vuelto.

101. RAH, Salazar y Castro, T-29, folios 359 vuelto y 360 . 
Rodrigo de Mendoza, cuarto duque de Pastrana (hijo de Ruy Gómez de Silva, tercer duque, a quien por sentencia de 1620 como después explicaré habían correspondido los mayorazgos incorporados al de Cifuentes), fundamentado en esta donación y la Chancillería de Valladolid sentenció a favor de la villa ${ }^{102}$. Más adelante, en 1747, el concejo de Huetos expuso a Fernando VI que de los ocho núcleos poblados (Ureña del Campo, El Villar y Fuentepinilla no estaban habitados) seis ya habían logrado su exención de Cifuentes y la solicitó también para sí: «ocurrís a mi real clemencia solicitando vuestra liuertad en la misma conformidad que la merecieron a mis gloriosos predecesores los otros seis lugares de Gárgoles de Auajo, Solanillos, Enche, Ruguilla, Gárgoles de Arriua y La Olmeda comprendidos igualmente en la venta que hizo el mencionado conde a fauor de la villa ${ }^{103}$; el monarca accedió a cambio de un donativo

102. RAH, Salazar y Castro, T-29, folios 356 a 383 vuelto. LAYNA SERRANO, Francisco (1955): Historia de la villa condal de Cifuentes (Guadalajara), página 178.

103. AGS, Dirección General del Tesoro, inventario 24, legajo 308, expediente 32, folios 2 vuelto y 3 . En los folios 1 vuelto a 2 vuelto los vecinos de Huetos exponen detalladamente las vejaciones que sufrían por parte de la villa de Cifuentes: «sufriendo la maior exclauitud a que os ha tenido y tiene constituidos el despótico gouierno que los alcaldes hordinarios de cada año en dicha villa ydean en perjuicio buestro tiranizando indeuidos derechos: por un tiempo momentáneo y lixero trauaxo asi como por hacer testamento y saca de él, de que exigen nouenta y seis reales, nouenta y quatro reales por los derechos de una mera comisión y auto provehido por el juez, aumentándose las costas muchas veces como fieron las referidas por competencias que voluntariamente mueben entre si los alcaldes hordinarios de Zifuentes despachando distintos jueces con repettidas comisiones como subcedió con el motiuo de hauer muerto, vajo de poder, Joseph, escrinano, vecino de dicho lugar, seiscientos reales por sola la diligencia de hauer pasado a él una audiencia de dicha villa por la tarde retirándose por la mañana del dia siguiente, sin disponer ni hacer las partijas de vienes que quedaron por muerte de Juan Moreno, que fue la causa de despachar la audiencia, y lleuando los excesiuos derechos que les parece por hacer los ymbentarios de uienes y demás diligencias judiciales que ocurren, sin que en caso alguno se pueda conseguir recino, de modo que asta con el pretexto de la muerte de un cura párroco vuestro, sin embargo de haner dejado testamento, despacharon dicha villa y sus alcaldes no sólo una sino dos audiencias, las que llegaron a un tiempo y boluiéndose sin actuar cosa alguna exijieron trescientos reales, executando iguales tiranías y uiolencias particularmente con cada vecino buestro como lo experimentó Juan Carrascosa, a quien por mera voluntariedad del alcalde de Cifuentes se le tubo veinte dias preso y le lleuó dos cabritos y quarenta reales y finalmente preualidos los alcaldes de dicha villa, de qualquiera lebe motino exixen $y$ molestan al comín como subçedió en el tránsito de la ynfanta a Francia, que os mandaron acudieseis con vastimentos por la dicha villa de Cifuentes quedándose ésta con ello, de que se ha cobrado corta cantidad a costa de ynfinitas extorsiones. Y en la próxima última leba que se mandó hacer repartió dicha villa al lugar un quarto o tercio de soldado y por él pidieron y cobraron seiscientos sesenta y seis reales $y$, despachada audiencia de ella, por condución y derechos exijió lo que quiso sin uastar que el correxidor de Guadalaxara declarase que por hauer satisfecho el lugar cien reales no devia contribuir a más gastos, pues dicha audiencia hizo pagar quatrocientos reales por razón de dicha condución, no hauiendo seguido Huetos su derecho por euitar la indignación de dicha villa y sus alcaldes, que posteriormente os sacrificase en odio de su defensa, que es un diseño de lo que executáis en los demás asumptos y negocios en que se interesa dicha villa de Cifuentes y sus vecinos. Y últimamente pudierais referir infinitos exemplares de las tiranas opresiones y uiolencias que padecéis con que os vais diariamente imposibilitando más y más, antecedentes que ineuitablemente han de ocasionar vuestra despoblación, precisando a los vecinos que oi han quedado, a desamparar el lugar para huir de tan intolerable seruidumbre»). 
de 225.000 maravedíes y bajo la condición de que Huetos pagara a Cifuentes la parte que le correspondiera de los 200.000 maravedíes que en 1479 esta villa había entregado a Juan de Silva ${ }^{104}$. El 1 de julio de 1751 se completaron estas exenciones al obtener la suya Sotoca de Tajo tras servir al rey con 210.000 maravedíes: «os hago villa de por si y sobre sí con jurisdición ciuil y criminal, alta y baja, mero mixto imperio en primera instancia para que los alcaldes ordinarios y demás oficiales de vuestro Aiuntamiento la puedan usar y ejercer en vos, la dicha villa de Sotoca, y en vuestro término y territorio. [...] Y os doy y concedo licencia y facultad, poder y autoridad para que desde el dia de la data de esta mi carta en adelante, juntos en vuestro Aiuntamiento, podáis nombrar alcaldes ordinarios, rexidores, procurador general, escribano y los demás oficiales de Justicia que fueren necesarios para vuestro gobierno, guardando en dicha elección lo que se hubiese practicado asta aqui en quanto a la regalia y demás derechos del referido conde de Zifuentes y sus sucesores sin exceder de ello en cosa alguna [...] sin que el alcalde maior, ordinarios y demás ministros de Justicia de la de Zifuentes se puedan entrometer a usar dicha jurisdición ciuil ni criminal en vos, la citada villa de Sotoca, ni en el mencionado vuestro término y territorio que tubiereis señalado o se os señalare como queda preuenido. [...] Y permito y quiero que podáis poner y pongáis orca, picota y cuchillo y las otras insignias de jurisdición que se han acostumbrado poner por lo pasado y se acostumbran al presente en las otras villas que tienen y usan de jurisdición ciuil y criminal, alta y baja, mero mixto imperio en dicha primera instancia y que por esto y todo lo demás contenido en esta mi carta en las partes donde tocare se os guarden y hagan guardar todas las preheminencias, exempciones, prerrogatibas e immunidades que se guardan y han guardado a las otras villas de estos mis reynos» ${ }^{105}$.

Volviendo al tercer conde, en 1504 Juan de Silva y su mujer Catalina de Toledo hicieron el cuarto mayorazgo del condado de Cifuentes agregando los bienes comprados a Alfonso Carrillo así como Escamilla (pueblo algo al sur del concejo de Atienza, adquirido en 1498 de Pedro Gómez Manrique, señor de Valdezcaray, aunque hasta 1508 no terminarán los pleitos que originó su compra ${ }^{106}$ ) y la mitad de Ciruelos (pueblo hoy en la provincia de Toledo cuya otra mitad ya poseían los Silva): «juntamos y añadimos e incorporamos en los dichos mayorazgos e en cada uno dellos los bienes

104. AGS, Dirección General del Tesoro, inventario 24, legajo 308, expediente 32, folios 3 a 5.

105. AGS, Dirección General del Tesoro, inventario 24, legajo 308, expediente 64, folios 3 a 4 vuelto.

106. La Historia de Escamilla no la recojo aquí por caer fuera de los concejos de Atienza y Medinaceli y de la extremadura castellana. Se puede seguir en LAYNA SERRANO, Francisco (1994 [1933]): Castillos de Guadalajara, páginas 368 a 372, y los problemas que originó su compra por el conde de Cifuentes en RIESCO DE ITURRI, Maria Begoña (1992): «Constitución y organización de un señorío nobiliario en el obispado de Sigüenza a finales de la Edad Media: el condado de Cifuentes» en Wad-al-Hayara 19, páginas 215 a 218 y (1996): Nobleza y señorios en la Castilla centro-oriental en la Baja Edad Media (siglos XIV y XV), páginas 1008 a 10 [1. Sobre el castillo de Escamilla LAYNA SERRANO, Francisco (1994 [1933]): Castillos de Guadalajara, páginas 367 y 368; ESPINOSA DE LOS MONTEROS MARTíN, Juan y MARTIN-ARTAJO SARACHO, Luis (coords.) (1974): Corpus de castillos medievales de Castilla, página 118 y Herrera CASADO, Antonio (2000): Guía de campo de los castillos de Guadalajara, páginas 138 y 139 . 
y cosas siguientes: primeramente las aldeas e lugares que dizen de Gárgoles de Suso $e$ Gárgoles de Yuso y lugares de Sotoca y el lugar de Enche y el lugar de Solanillos y el lugar del Olmeda e la villa de Escamilla con su fortaleza e la mitad del lugar de Ciruelos, que es en el arçobispado de Toledo, que yo, el dicho conde, compré de Ysabel de la Cadena, por quanto la otra mitad del dicho lugar es del dicho mayorazgo antiguo» ${ }^{107}$.

Después de hecho este mayorazgo Juan de Silva compró Alaminos (1508) y Renales (1509) a Ruy Sánchez de Torres. Los Torres eran sorianos de nación, por ello Juan de Torres, señor de Retortillo de Soria, como tutor de su yerno y sobrino segundo Ruy Sánchez de Torres, no mostró el menor interés en conservar el señorío de Renales y Alaminos, dos pequeños pueblos en el valle del Tajuña distantes entre sí unos quince kilómetros. Respecto a Alaminos, Juan de Torres solicitó y obtuvo permiso el 12 de mayo de 1508 de la reina Juana «para que como tutor de Rui Sánchez de Torres, su yerno, hijo de Garcia de Torres, pudiese vender a qualquier persona o personas que quisiese la villa de Alaminos con todo lo a ella perteneziente, que hera de el dicho menor, para pagar de lo que por ella le diesen, lo que costase la villa de Almenar, 4 leguas de Soria, que el susodicho [Juan de Torres] havia comprado para el dicho menor por serle de más utilidad que la dicha villa de Alaminos») ${ }^{108}$ (este documento se inventarió en el legajo 2058 de Osuna aunque atribuyéndolo en lugar de a la reina Juana a un tal «señor rey don Juan» ${ }^{109}$ ). Seis días después vendía Alaminos a Juan de Silva: «por ende yo, el dicho Juan de Torres, alcalde de Ponferrada, como tal tutor susodicho e por virtud de la dicha lizencia e facultad para lo de yuso contenido dada e conzedida por su alteza, otorgo e conozco por esta presente carta que vendo de juro e por juro de eredad para agora e para siempre jamás a vos, el muy magnifico señor don Juan de Silva, conde de Cifuentes, alférez mayor de Castilla, alférez mayor de Castilla (sic) por la reyna nuestra señora, toda la villa de Alaminos que es en el obispado de Sigüenza, la qual el dicho Ruy Sánchez de Torres, mi menor, ovo e heredó del dicho García de Torres, alcalde de Medinaceli, ya difunto, con sus vasallos e juredizión cevil e creminal e mero misto ymperio con todos sus términos e prados e pastos e exidos e abrevaderos e heredamientos e tierras de pan llevar o non llevar e con todos los pechos e derechos e tributos, imposiziones e martiniega e con todas las otras cosas e cada una dellas que en la dicha villa de Alaminos e en sus términos pertenescen e pueden pertenescer al dicho Ruy Sánchez de Torres, mi menor, en qualquier manera, dende la oja del árbol asta la piedra del agua $\rangle^{110}$. Según el historiador del legajo 3329

107. AHN, Nobleza, Osuna, legajo 2501, expediente 10, documento 1 , folio 29 vueito, documento inventariado en el legajo 2058, expediente 1, documento 1, con el número 39. RIESCO DE ITURRI, María Begoña (1996): Nobleza y señorios en la Castilla centro-oriental en la Baja Edad Media (siglos XIV y $X V)$, páginas 204 y 205.

108. AHN, Nobleza, Osuna, legajo 2066, expediente 6.

109. AHN, Nobleza, Osuna, legajo 2058, expediente 1, documento 1, número 119.

110. AHN, Nobleza, Osuna, legajo 2066, expediente 10, folios 11 a 12. Un traslado de este documento se inventarió en AHN, Nobleza, Osuna, legajo 2058, expediente 1, documento1, número 116. 
de Osuna «el señorío de Alaminos pertenecía a García de Torres, [...] cuio tutor, Juan de Torres, alcayde de Ponferrada, señor de Retortillo y de Pumar, y su suegro a un tienpo, con facultad de la reyna doña Juana dada en Burgos a 12 de mayo de 1508 , firmada del Rey Católico, su padre, y de Lope Conchillos, su secretario, para vender dicha villa y pagar con ella la villa de Almenar, a quatro leguas de Soria, que le era de más utilidad que la de Alaminos, vendió a don Juan de Silva, conde de Cifuentes, esta villa en Burgos a 18 de mayo de dicho año 1508 ante Gonzalo de Córdoba, esscriuano, con vasallos, jurisdición, rentas, pechos, martiniega y demás perteneciente en precio de 750 U marauedís, de que tomó posesión el conde en 9 de junio del mismo año»" . Máximo Diago Hernando recoge también que Ruy Sánchez de Torres «vendió Alaminos para comprar Almenar» y apostilla: «fortaleza que le interesaba controlar a su suegro Juan de Torres vecino de Soria» ${ }^{12}$. María Begoña Riesco de Iturri estudió con detalle esta venta y el proceso de subasta que tuvo lugar en Burgos ${ }^{113}$; dice que la subasta se realizó entre los días 15 y 17 de mayo de 1505 lo que entiendo como errata por 1508 .

Casi un año después, el 24 de marzo de 1509, Ruy Sánchez de Torres con licencia de su tutor y suegro Juan de Torres, vendió también al tercer conde de Cifuentes, el señorío de Renales por un millón de maravedíes: «sepan quantos esta carta de venta bieren cómo yo, Rui Sánchez de Torres, hijo legitimo de Garzía de Torres ${ }^{114}$, alcayde que fue de Medinazeli, defunto que Dios haya, vezino de la ciudad de Soria, con lizenzia e autoridad e espreso consentimiento que primeramente pido e demando a vos, Joán de Torres, alcayde de Ponferrada, curador que soys de mi persona e vienes, [...] otorgo e conozco que bendo por juro de heredad para agora e de aquí adelante, para siempre jamás a vos, el muy magnífico señor don Juan de Silba, conde de Zifuentes, alférez mayor de Castilla, para vos e buestros herederos e subzesores, la villa de Renales que es en el obispado de Sigüenza, que es zerca de Torrequadrada e de el ducado de Medinazeli, con todos los vasallos del dicho lugar e con todos sus términos e labranzas e serbidumbres a la dicha villa pertenezientes e con todos los pechos e derechos e renthas e recaudaziones que rinde la dicha villa, ordinarias e extrahordinarios e con todo el mando e señorio e con la Justizia de la dicha villa, zebil e criminal, alta e baja e mero misto imperio e con dos mill marauedis de juro que en la dicha villa tengo situados en las alcabalas e terzias, por prebilegio de su alteza, e ansi mismo con los heredamientos e tierras e términos e prados e pastos e montes e

11. AHN, Nobleza, Osuna, legajo 3329, expediente 2, pie 9, folio 9 vuelto.

112. Diago Hernando, Máximo (1992): La extremadura soriana y su ámbito a fines de la Edad Media, página 863.

113. RiesCO DE ITURRI, María Begoña (1992): «Constitución y organización de un señorío nobiliario en el obispado de Sigüenza a finales de la Edad Media: el condado de Cifuentes» en Wad-al-Hayara 19, páginas 214 y 215 y (1996): Nobleza y señoríos en la Castilla centro-oriental en la Baja Edad Media (siglos XIV Y XV), páginas 1006 y 1007. El texto de 1996 apenas amplía unas frases el de 1992.

114. Ruy Sánchez de Torres era hijo bastardo pero fue legitimado el 20 de diciembre de 1494 (RAH, Salazar y Castro, M-1, folio 128 vuelto). 
aguas corrientes e bertientes, estantes e manantes e con el molino que está en el sitio e término de villa Cabras, todo a humo muerto, [...] por preszio e contía de un quento de maravedis de la moneda usual corriente en Castilla ${ }^{115}$. Este documento fue utilizado por el historiador del legajo 3329 de Osuna; también por María Begoña Riesco de Iturri que no indica que Ruy Sánchez de Torres aún estaba bajo la tutela de su suegro ${ }^{116}$. En el inventario del Archivo de Cifuentes están registrados dos traslados de la venta así como las capitulaciones firmadas por Juan de Silva y Juan de Torres y la toma de posesión de Renales por el tercer conde de Cifuentes ${ }^{117}$. Aldara de Torres, pronto viuda de Ruy Sánchez de Torres y tutora de sus hijos García y María, pleiteó a causa de esta venta con Fernando de Silva, cuarto conde de Cifuentes, hasta que la Chancillería de Valladolid dio su sentencia el 6 de agosto de 1551 a favor del conde ${ }^{118}$.

En 1512 don Juan adquirió Torrecuadrada de los Valles de Antonio de la Cerda, nieto de Luis de la Cerda, tercer conde de Medinaceli, quien había obtenido permiso de la reina Juana el 2 de noviembre para poder venderla ${ }^{119}$. Ese día ya estaba de acuerdo con Juan de Silva en todos los aspectos del contrato y se firmó una escritura de trueque por la que don Antonio entregaba Torrecuadrada de los Valles con su fortaleza y la dehesa de Termillo a cambio de 60.000 maravedíes de juro de heredad situados en las alcabalas de Toledo más otros 80.000 maravedíes en efectivo: «don Antonio de la Cerda dio al conde de Çifuentes don Juan de Ssilua la villa de Torrequadrada con su fortaleza e con la dehessa de Termillo e con todo lo demás a ella perteneçiente por ssesenta mill marauedís de juro de heredad perpetuos en cada un año sobre las alcaualas de Toledo e más ochenta mill maravedis en dinero que le dio el dicho conde. Su fecha en la ciudad de Burgos a dos de noviembe de mill y quinientos y onçe $a \tilde{n} o s\rangle^{120}$. El documento definitivo se expidió el 22 de enero de 1512 incluyendo en la venta 2000 maravedíes de juro que no figuraban en el acuerdo anterior: «una carta de venta que pareze hauer otorgado don Antonio de la Zerda, señor de Torrequadrada, hijo de don Juan de la Çerda, y en fabor de don Juan de Ssilua, conde de Çifuentes, de la villa de Torrequadrada con dos mill marauedis de juro. Su fecha en la villa de Cifuentes en veinte y dos de henero de mill y quinientos y doçe ante Gonçalo de Rrio, escriuano, en veynte oxas. Y siguisse (sic) la possesión que sse tomó de la dicha villa

115. AHN, Nobleza, Osuna, legajo 2066, expediente 12, folios 1 a 3 vuelto.

116. AHN, Nobleza, Osuna, legajo 3329, expediente 2, pie 9, folio 10. RIEsCO DE ITURRI, María Begoña (1992): «Constitución y organización de un señorio nobiliario en el obispado de Sigüenza a finales de la Edad Media: el condado de Cifuentes» en Wad-al-Hayara 19, página 215 y el mismo texto en (1996): Nobleza y señorios en la Castilla centro-oriental en la Baja Edad Media (siglos XIV y XV), página 1007.

117. AHN, Nobleza, Osuna, legajo 2058, expediente 1, documento 1, números 106 y 109 (traslados de la venta; en el segundo dice Luis Sánchez de Torres por errata), 107 (capitulación) y 108 (toma de posesión).

118. Noticia de la sentencia en AHN, Nobleza, Osuna, legajo 2058, expediente 1, documento 1, número 28, y documentación sobre el pleito en el número 29 y en RAH, Salazar y Castro, M-1, folio 129.

119. AHN, Nobleza, Osuna, legajo 2058, expediente 1, documento 1, números 432 y 435.

120. AHN, Nobleza, Osuna, legajo 2058, expediente 1, documento 1, número 436. 
de Torrequadrada por parte de el dicho conde en otras quatro oxas con la del signo. Yten un testimonio de unos requerimientos hechos por parte de el dicho conde de Cifuentes don Juan de Silua a los vecinos de Torrequadrada sobre la paga de los dos mill marauedís de juro» ${ }^{\mid 21}$. La compra de este señorío por el tercer conde de Cifuentes ha de situarse a la vista de estos documentos en enero de 1512 y no en 1490 como hace Herrera Casado ${ }^{122}$ o el 18 de mayo de 1508 según dice Martínez Díez ${ }^{123}$.

Alaminos, Renales y Torrecuadrada de los Valles procedían de compras y eran por tanto bienes libres no vinculados a los mayorazgos de Cifuentes; por eso Juan de Silva en su último testamento del 5 de febrero de 1512 pudo dejárselos a Juan, su hijo tercero, con la condición de que si moría sin descendencia legítima volvieran a los condes de Cifuentes como recoge Riesco de Iturri ${ }^{124}$ : «otrosí quiero y mando que don Juan de Silva, mi hijo, aia y tenga en su legitima los mis logares que llaman Torrequadrada y Revales (sic) y Alaminos con este vínculo y condición: que si el dicho don Juan de Silva, mi hijo, muriere sin hijos legítimos, que buelvan los dichos lugares a mi maiorazgo y queden incorporados en él para siempre jamás por vía de maiorazgo con las cláusulas, vínculos y condiciones y submisiones contenidas en el dicho mi maiorazgo y más con esta condición: que si el llamado a mi maiorazgo en qualquier tiempo le quisiere dar y diere en otra parte equivalencia en bienes raices tales y tan buenos a vista de dos personas nombradas y puestas por amas partes, que sea obligado el dicho don Juan de Silva, mi hijo, a le dar y dejar los dichos mis logares de Torrequadraday Revales y Alaminos porque están tan juntos con ésta mi villa de Cifuentes. Y en tal caso avidos los dichos logares en la manera que dicha es, mando que los dichos logares queden metidos y se metan en mi maiorazgo con los vinculos y condiciones y firmezas en él contenidas» ${ }^{125}$.

Pero otra cláusula del mismo testamento que no cita Riesco de Iturri ordenaba ceder Renales a Fabián de Salazar: «otrosi mando y es mi voluntad que se cumpla con Fabián de Salazar lo que yo con él tengo asentado segund está firmado de mi nombre. $Y$ para que pueda quedar y quede mi lugar de Renales libre al heredero a quien yo lo mando en este mi testamento, mando que los $100 \mathrm{U}$ marauedis de juro al quitar que yo tengo en tierra de Molina, que déstos se paguen en cada un año todos los dichos I00U marauedis al dicho Fabián de Salazar en los siete años primeros siguientes: las 700 marauedís que yo tengo asentado de le dar por la dicha cédula firmada de

121. AHN, Nobleza, Osuna, legajo 2058, expediente 1, documento 1, número 433.

122. HeRrera CASADO, Antonio (1988 [1983]): Crónica y guía de la provincia de Guadalajara, páginas 640 y 641 .

123. MARTINEz Diez, Gonzalo (1983): Las comunidades de villa y tierra de la extremadura castellana (estudio histórico-geográfico), página 221.

124. RIESCO DE ITURRI, Matía Begoña (1996): Nobleza y señorios en la Castilla centro-oriental en la Baja Edad Media (siglos XIV y XV), páginas 88 y 89.

125. RAH, Salazar y Castro, M-94, folios 146 vuelto y 147 y extracto en AHN, Nobleza, Osuna, legajo 2501, expediente 10 , documento 1 , folios 25 vuelto a 26 vuelto. 
mi nombre y así quede libre el dicho logar de Renales» ${ }^{126}$. Don Juan murió nada más hacer testamento y, según se desprende de documentos hasta ahora inéditos, el nuevo conde Fernando de Silva se obligó tres semanas después a entregar Renales a Fabián de Salazar una vez se casara su hermana María de Silva con Juan de la Cerda, segundo duque de Medinaceli (viudo de Mencía Manuel de Portugal, hija de los condes de Faro), en recompensa por el trabajo de don Fabián para lograr ese matrimonio ${ }^{127}$. Hasta 1540 no recuperó Fernando de Silva el lugar tras pagar a María de Esquivel, viuda de Fabián de Salazar y tutora de su nieta Beatriz de Salazar, los 700.000 maravedíes fijados por su padre: «una carta de pago y finiquito que pareçe hauer otorgado María de Esquibel, viuda de Fabián de Ssalaçar por ssí y como curadora de doña Beatriz de Salaçar, su nieta, en fabor de don Fernando de Ssilua, conde de Cifuentes, de setecientas mill marauedís por rraçón de la rrestituçión de la villa de Ranales (sic) que sse le abia dado por el dicho conde al dicho Fabián de Ssalazar porque efetuasse el cassamiento del duque de Medina Çeli con doña Maria de Ssilua. Su fecha en Medina Çeli en veinte y ocho de abril de mill y quinientos y quarenta ante Diego de la Peña, escriuano puiblico de la dicha villa, en quatro foxas» ${ }^{128}$.

Además Juan murió pronto sin herederos y su madre Catalina de Toledo en 1523, ya viuda, otorgó un quinto mayorazgo de Cifuentes agregando Alaminos, Renales y Torrecuadrada de los Valles en favor de Fernando de Silva, cuarto conde de Cifuentes y señor de los mayorazgos de sus antepasados desde la muerte de su padre: «usando de la facultad que por las leyes de nuestros reynos yo tengo para poder mejorar en el tercio e remanente del quinto de mis bienes y ansi mismo usando de la dicha facultad de suso incorporada y en aquella via e forma que sea más prouechosa al dicho conde de Cifuentes don Fernando de Silua, mi hijo, e a los que después dél han de suceder en su mayorazgo, por la presente le mando los dichos lugares de Torrequadrada y Renales e Alaminos con todo lo que en ellos y en cada uno dellos a mi me pertenece e puede pertenecer en ellos y en cada uno dellos como heredera del dicho don Iuan mi hijo para que el dicho conde los tenga e possea por todos los dias de su vida por vía e título de mayorazgo con los vinculos e prohibiciones, sostituciones e restituciones que tienen las otras villas y lugares e bienes del mayorazgo que ouo por fallecimiento del dicho conde mi señor, su padre, que sea en gloria ${ }^{129}$. La inclusión en este mayorazgo de Renales, propio ya digo de Fabián de Salazar, se debe seguramente al deseo de doña Catalina y su hijo de recuperar el lugar y a las posibles negociaciones de compra que ya habrían comenzado. Renales junto con Alaminos y Torrecuadrada de los Valles volvió a ser agregado al mayorazgo de Cifuentes en 1545 para evitar problemas legales como enseguida explicaré.

126. RAH, Salazar y Castro, M-94, folio 137 y extracto en AHN, Nobleza, Osuna, legajo 2501, expediente 10 , documento 1 , folios 25 vuelto a 26 vuelto.

127. AHN, Nobleza, Osuna, legajo 2029, expediente 2, documentos 1 a 3. Esta donación aparece inventariada en el legajo 2058, expediente 1, documento 1 con el número 416.

128. AHN, Nobleza, Osuna, legajo 2058, expediente 1, documento 1, número 417.

129. AHN, Nobleza, Osuna, legajo 2501, expediente 10, documento 1, folio 35 vuelto. 
Fernando de Silva continuó incrementando su patrimonio con la compra el 5 de mayo de 1525 de El Sotillo y Moranchel a Gil de Andrade: «sepan quantos esta carta de bención vieren cómo yo, Gil de Andrada, vecino y morador de la villa de Medinaceli, y de mi propia e agradable y espontánea voluntad, otorgo y conozco que robro e bendo e traspaso por juro de heredad para agora y para siempre jamás a vos, el muy magnifico señor don Fernando de Silba, conde de Cifuentes, e para buestros herederos e subcesores, combiene a saber: las mis villas y lugares de Moranchel y del Sotillo, que están y son situados en el obispado de Sigüenza [...] por prescio y contia de 2 quentos de maravedís, el 1 quento 400.000 maravedis por la dicha villa del Sotillo e vassallos e jurisdizión ceuil e criminal e pechos y derechos e censo e todo lo demás de suso contenido, y por la dicha villa de Moranchel e juresdizión ceuil e criminal e vassallos della e pechos e derechos e seruicios de suso declarados, 600.000 maraue$d i s\rangle^{130}$. Así lo citan brevemente Herrera Casado ${ }^{131}$ y Layna Serrano ${ }^{132}$ que menciona la capitulación del 24 de abril entre Gil de Andrade y don Fernando con las condiciones de la venta, que está copiada en la colección Salazar ${ }^{133}$. Juana de Castilla, mujer de Gil de Andrade, ratificó este contrato el mismo día ${ }^{134}$. El documento de venta señala los términos con los que lindan El Sotillo y Moranchel y da cuenta de tres aldeas dependientes de E1 Sotillo: «y á y tiene la dicha villa de Moranchel y su término por linderos e límites: de la una parte el término de la dicha villa de Çifuentes y por la otra parte el término del lugar de Masegoso y por la otra parte el término de la villa de Las Yviernas; e de la dicha villa del Sotillo e su término e anexos, que son Valdearanze y Valdehuentes y Ostinilla, que tienen e han por linderos por la una parte el término de la villa de Cifuentes e por la otra parte el término de la dicha villa de Las Yviernas y el término de la dicha villa de Torre Quadrada» ${ }^{135}$.

Además don Fernando adquirió Yela del monasterio de San Blas de Villaviciosa de Tajuña. El 14 de marzo de 1533 los monjes otorgaron la carta de venta: «yten una escriptura de venta que pareçe hauer otorgado el prior y frayles de el monasterio de Ssan Blas de Villa Viçiossa de la horden de San Jerónimo en fabor de don Fernando de Silua, conde de Çifuentes, de la villa de Yela con su término y todo lo a ella perte-

130. RAH, Salazar y Castro, M-25, folios 132 a 133, documento inventariado en AHN, Nobleza, Osuna, legajo 2058, expediente 1, documento 1, número 45. Noticia en RAH, Salazar y Castro, M-1, folio 129.

131. Herrera CASADO, Antonio (1988 [1983]): Crónica y guía de la provincia de Guadalajara, página 315

132. Layna Serrano, Francisco (1955): Historia de la villa condal de Cifuentes (Guadalajara), páginas 121 y 122

133. RAH, Salazar y Castro, M-25, folios 138 vuelto a 140 .

134. RAH, Salazar y Castro, M-1, 130 vuelto.

135. RAH, Salazar y Castro, M-25, folios 132 y 132 vuelto. Valdearanze ha de ser un lugar cercano al santuario de Nuestra Señora de Aranz, y Valdehuentes un despoblado próximo a la fuente de Valdefuentes en el noroeste del término de El Sotillo. Ostinilla debe identificarse con el despoblado de Estinilla que cita Martínez Díez, dos kilómetros al norte de El Sotillo dentro de su término municipal (Las comunidades de villa y tierra de la extremadura castellana (estudio histórico-geográfico), página 227) 
neçiente, su fecha en el dicho monasterio en catorce de março de mill y quinientos y treynta y tres ante Juan de Salamanca, escriuano real y público de Çifuentes, en treynta y quatro ojas con la del sino ${ }^{136}$. Los contactos entre ambas partes habían empezado al menos un año antes, pues el 4 de abril de 1532 fray Cristóbal de la Trinidad y fray Juan Bautista fueron apoderados por el monasterio para la venta ${ }^{137}$. Antes de concluirla los monjes hubieron de obtener infinidad de permisos tanto eclesiásticos (muchos de ellos de Roma) como de los herederos de Alfonso Carrillo de Acuña (es muy probable que éste al hacer la donación impusiera ciertas cláusulas al monasterio tratando de impedir eventuales enajenaciones), lo que provocó que hasta el 14 de marzo de 1536 Fernando de Silva no tomara posesión del lugar ${ }^{138}$. El cuarto conde de Cifuentes quiso también comprar Carrascosa de Tajo al monasterio de Ovila pero el lugar acabó integrándose en el ducado de Medinaceli ${ }^{139}$.

El 13 de abril de 1545 otorgó testamento en Madrid por el que constituía el sexto mayorazgo del condado de Cifuentes repitiendo la agregación de Alaminos, Renales y Torrecuadrada de los Valles y añadiendo El Sotillo, Moranchel y Yela: «digo que incorporo, subrogo, meto y pongo en el dicho mi mayorazgo antiguo las villas de Renales y Alaminos y Torrequadrada y El Sotillo y Moranchel e Yela con el mero mixto imperio, territorio, juridición alta y vaja, cebil y criminal, rentas, tributos y todo lo que a las dichas villas es anejo y pertenescienter ${ }^{140}$.

136. AHN, Nobleza, Osuna, legajo 2058, expediente 1, documento 1, número 357.

137. AHN, Nobleza, Osuna, legajo 2058, expediente 1, documento 1, número 362.

138. AHN, Nobleza, Osuna, legajo 2058, expediente 1, documento 1, número 360

139. El 10 de agosto de 1532 Fernando de Silva dio poder a su primo Diego de Molina, alcaide de Atienza, para negociar un acuerdo (AHN, Nobleza, Osuna, legajo 2075, expediente 7) que no llegó a producirse según apunta Layna basándose en la Historia genealógica de la Casa de Silva de Salazar y Castro (El monasterio de Ovila, página 110 e Historia de la villa condal de Cifuentes (Guadalajara), página 121). En las Relaciones de Felipe II los vecinos de Carrascosa de Tajo «al octavo capitulo respondieron que esta villa es del duque de Medinaceli y la compró su padre abrá diez años poco más o menos tiempo de los frailes del monasterio de Nuestra Señora de Obila que es de la orden del Cister) (ORTIz GARCiA, Antonio (2002): Relaciones topográficas de la provincia de Guadalajara, edición digital y LAYNA SERRANO, Francisco (1998 [1932]): El monasterio de Ovila, páginas 110 y 123). Los encuestadores del rey pasaron por Carrascosa de Tajo el 22 de diciembre de 1578 siendo Juan de la Cerda quinto duque de Medinaceli, por lo que la compra tuvo que hacerse hacia 1568 cuando aún era cuarto duque su padre y tocayo Juan de la Cerda que murió en 1575 . Por ello el 3 de noviembre de 1570 ya figura don Juan como señor de Carrascosa de Tajo: «la villa de Carrascosa del Rrío, que diz ques del dicho duque [don Juan de la Zerda, cuarto duque de Medinazeli]) (AGS, Mercedes, privilegios, ventas y confirmaciones, legajo 304, expediente 8, folio 1 vuelto).

140. AHN, Nobleza, Osuna, legajo 2501 , expediente 10 , documento 1, folios 38 vuelto y 39 y RAH, Salazar y Castro, M-94, folio 205. Inventariado en AHN, Nobleza, Osuna, legajo 2058, expediente 1, documento 1 con el número 40. 
A Juan de Silva, quinto conde de Cifuentes, hijo de Fernando de Silva y Catalina de Andrade ${ }^{141}$, le sucedió su hijo Fernando de Silva, sexto conde ${ }^{142}$, que era el titular de Cifuentes cuando Pedro Jerónimo de Aponte escribió su Libro de los linages de España: «don Fernando de Silua, conde de Cifuentes. Posee el estado» ${ }^{143}$ y que en 1579 acordó la compra de Barriopedro con Bernabé Centurión tras su desmembración de Sigüenza completando así las posesiones de los Silva en la Alcarria. Barriopedro había pertenecido a los obispos de Sigüenza y fue desmembrado por Felipe II el 10 de septiembre de $1579^{144}$. Tras su reincorporación a la Corona el rey decidió venderlo al conde de Cifuentes con la intervención del prestamista Bernabé Centurión ${ }^{145}$. El privilegio real de venta de Barriopedro a Fernando de Silva se retrasó hasta 1583: «yten sse ynventarió la carta de venta que Ssu Magestad el rey Felipe segundo hiço y dio firmada de su mano y ssellada con ssu ssello de plomo pendiente y rrefrendado de Pedro de Escobedo, su ssecretario, y passada por los libros de la rrazón, su fecha en Madrid a doçe de agosto de mill y quinientos y ochenta y tres años, en fabor de don Fernando de Ssilua, conde de Çifuentes. Está escripta en pergamino en çiento y cinquenta y cinco foxas y enquadernada, yluminada la primera foxa, por la qual Su Magestad le vendió la villa de Varriopedro con sus vassallos, juridiçión y rrentas por preçio de ochoçientas y cinquenta $y$ dos mill $y$ çien marauedís ${ }^{146}$. Sin embargo el conde disfrutaba de Barriopedro desde el 5 de diciembre de 1580 cuando Pero Díaz de Castañeda, comisionado de Felipe II, le había entregado la posesión ${ }^{147}$.

La salud de don Fernando estaba muy mermada y murió el 21 de mayo de $1590^{148}$ después de haber testado en el castillo de Milán el 14 de julio de $1588^{149}$. A partir de aquí Layna explica con detalle que «el supuesto de que la degeneración fisica de la rama mayor de la Casa de Silva amenazaba con la pronta extinción de esa línea quedó muy pronto confirmado». De su hijo Juan Baltasar de los Reyes, séptimo conde, nacido el día de Reyes de 1581, dice que «era raquítico y enfermizo, frecuentes enfermedades infantiles retrasaron considerablemente su lento desarrollo corporal, años más tarde quedó ciego a consecuencia de la viruela y durante su corta vida más días

141. AHN, Nobleza, Osuna, legajo 2074, expediente 3, documento 1 y carpeta de genealogías 3, documento 9. Catalina de Andrade era hija de Fernando de Andrade, señor de Puentedeume y Ferrol, y de Francisca de Estúñiga Ulloa, segunda condesa de Monterrey y señora de Galve de Sorbe.

142. Casó en 1571 con Blanca de la Cerda, hija de Juan de la Cerda, cuarto duque de Medinaceli.

143. RAH, Pellicer, tomo XXIX, folio 411.

144. AGS, Mercedes, privilegios, ventas y confirmaciones, legajo 264, expediente 23, documento 2 .

145. AGS, Mercedes, privilegios, ventas y confirmaciones, legajo 264, expediente 23 , documento 1 , folios 31 y 31 vuelto y AHN, Nobleza, Osuna, legajo 2058, expediente 1, documento 1, número 95.

146. AHN, Nobleza, Osuna, legajo 2058, expediente 1, documento 1, número 91.

147. AGS, Mercedes, privilegios, ventas y confirmaciones, legajo 264, expediente 23, documento 7 .

148. Gutiérrez Coronel, Diego (1946 [1772]): Historia genealógica de la Casa de Mendoza, página 529

y Layna Serrano, Francisco (1955): Historia de la villa condal de Cifuentes (Guadalajara), páginas 143 y 144 .

149. RAH, Salazar y Castro, M-94, folios 213 a 222 vuelto. 
fue atormentado por las dolencias que acariciado por la salud》》. No sale mejor parada su primera mujer, Francisca de Rojas, con la que se casó a los trece años y que «dehía ser también otra piltrafilla humana». Murió el conde en 1602 sin dejar descendencia y le sucedió su hermana Ana de Silva, octava condesa de Cifuentes, «la feble condesita doña Ana, flor juvenil prematuramente seca en tierra siciliana» ${ }^{i 50}$. Como apunta la genealogía de los Silva que se elaboró para el pleito que a continuación se produjo y que terminó con la división de los mayorazgos de Cifuentes entre sus condes y los duques de Pastrana, doña Ana «murió sin sucessión en 29 de março de $1606{ }^{\mid 5 !}$.

\section{LOS PLEITOS DE SUCESIÓN DEL SIGLO XVII (1606-1644)}

Los dos principales pretendientes que trataron de heredar el condado de Cifuentes fueron Ruy Gómez de Silva, tercer duque de Pastrana y señor de Mandayona, Miedes de Atienza y los lugares que habían sido del adelantado de Cazorla (como nieto de la princesa de Éboli, biznieto de Catalina de Silva y tataranieto de Fernando de Silva, cuarto conde de Cifuentes), y Pedro Girón de Silva, biznieto de Alfonso de Silva, segundo conde de Cifuentes ${ }^{152}$. La sentencia se pronunció en la Chancillería de Valladolid el 1 de julio de 1620 . En ella se adjudicaba el título de conde de Cifuentes y los bienes agregados hasta el segundo mayorazgo (el que hizo en 1458 Juan de Silva, primer conde: Cifuentes, Trillo, Valderrebollo, Val de San García, Fuentepinilla, Huetos y Ruguilla) a Pedro Girón de Silva: «en el pleito ques entre doña Antonia de Toledo, duquessa

150. Layna Serrano, Francisco (1955): Historia de la villa condal de Cifuentes (Guadalajara), páginas 144 y 146.

151. AHN, Nobleza, Osuna, carpeta de genealogias 3, documento 9.

152. Según el Archivo de la Real Chancilleria de Valladolid, Registro de ejecutorias, caja 2604, número 32, los otros seis pretendientes fueron Antonio Juan Luis de la Cerda, séptimo duque de Medinaceli (tataranicto de Maria de Silva, hija de Juan de Silva, tercer conde de Cifuentes); Diego de Silva, duque de Francavila y conde consorte de Salinas y Ribadeo (hijo de la princesa de Éboli y por tanto tío de Ruy Gómez de Silva); Catalina de Silva Pacheco (tataranieta de Alfonso de Silva, segundo conde de Cifuentes) y su hijo Julián de Cañas y Silva; Fernando Jacinto de Meneses Silva (retataranieto de Alfonso de Silva, segundo conde de Cifuentes, y más adelante undécimo conde); Sancho de la Cerda, marqués de Laguna de Cameros (tío abuelo del también pretendiente séptimo duque de Medinaceli y biznieto de Juan de Silva, tercer conde de Cifuentes). GuTiÉrRez Coronel, Diego (1946 [1772]): Historia genealógica de la Casa de Mendoza, páginas 531 y 532, sólo cita de éstos a Ruy Gómez de Silva, Pedro Girón de Silva y Juana Pacheco de Silva (madre de Fernando Jacinto de Meneses Silva) pero añade a Alonso Pacheco de Silva, canónigo de Santiago, hermano de Catalina de Silva Pacheco. En Layna Serrano, Francisco (1955): Historia de la villa condal de Cifuentes (Guadalajara), página 173, figuran Diego de Silva, duque de Francavila; Ruy Gómez de Silva, duque de Pastrana, y su hermano tercero Diego de Silva y Mendoza (que alegaba que su hermano mayor era caballero de una orden militar y por tanto le afectaba la prohibición de heredar de los religiosos); Alonso Pacheco de Silva, canónigo de Santiago, sus hermanas Catalina y Mariana y su sobrino Francisco Verdugo (hijo de Ana de Silva) para el caso de que él no pudiera heredar por ser clérigo; Juana Pacheco de Silva y su hijo recién nacido Fernando Jacinto de Meneses Silva; Pedro Girón de Silva (dice que era «hermano del mencionado canónigo» pero se trata en realidad del que después fue noveno conde, primo de Luis Pacheco de Silva, padre del canónigo: Alonso Pacheco de Silva y sus hermanos no eran Girón de apellido). 
de Medinaceli, como tutora de don Juan Antonio de la Cerda, duque de Medinaceli, su hijo, y Diego de Villalobos, su procurador, de la una parte, y don Pedro de Ssilua, conde de Cifuentes, y Antonio de Medina, su procurador; y Rrui Gómez de Ssilua y Mendoça y de la Çerda, príncipe de Medílito (sic), duque de Pastrana, y Pedro de Monrroi, su procurador; y don Francisco Berdugo de Ssilua y Pascual Veçerril, su procurador; y don Diego de Ssilua, conde de Ssalinas y Rriuadeo, duque de Francauila, y Ssebastián de Garnica (sic), su procurador; y don Juan de Cañas como marido y conjunta persona de doña Catalina de Silua Pacheco, y Pedro Vélez, su procurador; y don Fernando de Meneses y Gaspar Ximénez, su procurador, y don Juan de Cañas Silua y Andrés de Cañas, su curador, y Juan de Frechilla, su procurador; y don Ssancho de la Cerda, marqués de La Laguna en su ausencia y rreueldia, de la otra, ffallamos, atento los autos y méritos del processo deste dicho pleito, que los duques de Pastrana y Medinaceli y conde de Ssalinas y don Juan de Cañas como marido y conjunta perssona de doña Catalina de Ssilua y don Julián de Cañas, su hijo, y don Fernando de Meneses y don Sancho de la Cerda, marqués de La Laguna, no prouaron su intención y demanda como prouar les conuino en lo que de iusso se ará mençión e dámosla e pronunçiámosla por no prouada. Y quel dicho don Pedro Girón de Ssilua prouó sus execsiones y defensiones como por prouar le conuino [e] dámoslas e pronunçiámoslas por uien prouadas e en consequençia de lo qual absoluemos al dicho don Pedro Girón de Ssilua de la demanda contra él puesta de la dicha uilla de Cifuentes y lugares de su juridición y los demás términos e uienes contenidos en el mayorazgo que don Juan de Ssilua, primer conde de Cifuentes, con facultad real instituió y fundó en quinçe dias del mes de agosto del año de mill y quatoçientos (sic) y çinquenta y ocho en don Alfonsso de Silua, su hijo maior, e sus descendientes. Y ponemos perpetuo silencio a los dichos duques y demás consortes puestos en la caueça de esta sentençia, para que sobre ella no le pidan ni demanden cossa alguna aora ni en tienpo alguno ni de alguna manera. Y en quanto al maiorazgo de la mitad de Barçiençe que fundó el adelantado Alonsso Tenorio en catorçe de agosto de mill y quatroçientos y treinta y en quanto a la otra mitad del dicho lugar de Varçiençe de que fundó mayorazgo el conde don Juan de Silua por su testamento en quinçe de agosto de mill y quatroçientos y çinquenta y ocho y en quanto a la mitad de la uilla de Palaçuelos ( $\operatorname{sic}^{153}$ ) de que fundó mayorazgo doña Yssauel de Castañeda, condessa de Çifuentes, en diez y ocho de abril de mill y quatroçientos y ssesenta e dos, y de los vienes surrogados a ella y demás acrecentados por don Juan de Ssilua, terçero conde de Çifuentes, en el año passado de mill y quinientos y doçe y anssi mismo los acreçentados por el dicho don Juan de Silua y doña Catalina de Toledo, su muguer, en el maiorazgo que fundaron en quinçe de diçienbre de mill y quinientos y quatro y anssí mismo los acrecentados en el mayorazgo fecho por doña Catalina de Toledo, siendo biuda, en quinçe de maio de mill y quinientos y ueinte y tres y anssi mismo en quanto a los wienes acrecentados en el mayorazgo que

153. Lo que incorporó Isabel de Castañeda fue la mitad de Palos de la Frontera como ya señalé; en el folio 63 de esta misma ejecutoria se anota correctamente: «el maiorazgo de la mitad de la uilla de Palos que fundó doña Yssauel de Castañedà. 
hiço y fundó don Fernando de Silua, quarto conde de Cifuentes, en treçe de abril de mill y quinientos y quarenta y cinco, declaramos pertenecer todos los dichos vienes, maiorazgos y acrecentamientos al dicho duque de Pastrana para que los tenga e posea por vienes de mayorazgo con los vínculos e gravámenes contenidos en las dichas fundaciones y condenamos al dicho don Pedro Xirón de Silua a que lo [que de] aquéllos tubiere y poseiere se los buelua y entregue y rrestituia con los frutos que an rrentado y rrentaren desde la contestación asta la real entrega y asoluemos y damos por libre al dicho duque de Pastrana de la demanda contra él puesta de algunos en los dichos uienes por las dichas partes. [...] La qual dicha sentencia suso incorporada fue dada y pronunciada por los dichos nuestro pressidente y oidores estando haciendo audiencia pública en Valladolid a primero día del mes de jullio de mill y sseisçientos y ueinte años $\rangle^{154}$

Don Pedro era el heredero con más derechos al condado de Cifuentes pero no así a los acrecentamientos que hicieron sucesivamente Isabel de Castañeda, el tercer conde, Catalina de Toledo y el cuarto conde pues no descendía de ellos sino sólo de Alfonso de Silva, segundo conde. Por eso Gárgoles de Arriba, Gárgoles de Abajo, Sotoca de Tajo, Henche, Solanillos del Extremo, Olmeda del Extremo, Escamilla, Renales, Alaminos, Torrecuadrada de los Valles, E1 Sotillo, Moranchel y Yela, lugares agregados en los mayorazgos tercero, cuarto, quinto y sexto por unos Silva de los que no descendía don Pedro, fueron adjudicados a Ruy Gómez de Silva y se incorporaron al ducado de Pastrana.

Los pleitos continuaron con Pedro Girón de Silva, noveno conde de Cifuentes, y su hijo Alonso José de Silva Girón, décimo conde de Cifuentes ${ }^{155}$, que murió sin sucesión en 1644. Hubo un nuevo pleito que enfrentó a Rodrigo de Silva Mendoza, cuarto duque de Pastrana (hijo de don Ruy) y Fernando Jacinto de Meneses Silva (sobrino nieto del noveno conde de Cifuentes) ${ }^{156}$. En el mimo año 1644 se dio la sentencia que

154. Archivo de la Real Chancillería de Valladolid, Registro de ejecutorias, caja 2604, número 32, folios 62 y 62 vuelto.

155. El 22 de octubre de 1632 la Chancillería de Valladolid confirmó su sentencia de 1620 tras la apelación de Antonia de Toledo en nombre de su hijo Antonio Juan Luis de la Cerda, séptimo duque de Medinaceli (Archivo de la Real Chancilleria de Valladolid, Registro de ejecutorias, caja 2604, número 32, folio 72); el 20 de octubre de 1634 se despachó carta ejecutoria a favor de Rodrigo de Silva, cuarto duque de Pastrana, de los bienes adjudicados a su difunto padre Ruy Gómez de Silva en 1620 (Archivo de la Real Chancillería de Valladolid, Registro de ejecutorias, caja 2604, número 32); el 15 de diciembre de 1637 se dio carta ejecutoria a Alonso José de Silva Girón, décimo conde de Cifuentes, de los frutos y rentas que debía entregar a Rodrigo de Silva por el tiempo que los mayorazgos que se le adjudicaron en 1620 habian estado bajo la administración de su padre Pedro Girón de Silva, noveno conde (Archivo de la Real Chancillería de Valladolid, Registro de ejecutorias, caja 2659, número 50 y Pleitos civiles, escribanía de Alonso Rodríguez, pleitos fenecidos, caja 1970, número 2).

156. También concurrieron al pleito dos de los pretendientes de 1620: Antonio Juan Luis de la Cerda, séptimo duque de Medinaceli, y Alonso Pacheco de Silva, canónigo de Santiago (GuTlérRez Coronel, Diego (1946 [1772]): Historia genealógica de la Casa de Mendoza, página 534). Layna Serrano (Historia de la villa condal de Cifuentes (Guadalajara), página 177) alarga la lista: Julián de Cañas y Silva (hijo de Catalina de Silva Pacheco); Magdalena Girón de Silva (hermana del difunto Alonso José, décimo conde); Rodrigo de Silva, cuarto duque de Pastrana; Antonio Juan Luis de la Cerda, séptimo duque 
adjudicó el condado de Cifuentes a Fernando Jacinto de Meneses Silva y ratificó los lugares acrecentados a partir del tercer mayorazgo, en favor del duque de Pastrana ${ }^{157}$; aunque los pleitos continuaron hasta bien entrado el siglo XVIII, los señorios ya no volvieron a salir de la familia ${ }^{158}$.

Las sentencias de 1620 y 1644 que describe Layna dejan dos puntos oscuros: Sotoca de Tajo y Barriopedro. Sotoca de Tajo pertenece a los lugares acrecentados por Juan de Silva, tercer conde de Cifuentes, en el cuarto mayorazgo de 1504 y por ello pasó, como recogen las sentencias, a los duques de Pastrana pues ni Pedro Girón de Silva ni Fernando Jacinto de Meneses Silva descendían de ese tercer conde. Sin embargo en el manuscrito de la Renta del Tabaco de 1752 se atribuye a los condes de Cifuentes ${ }^{159}$, seguramente por errata. Más problemas plantea Barriopedro, adquirido en 1579 por Fernando de Silva, sexto conde de Cifuentes, que no era antepasado de Pedro Girón ni de Fernando Jacinto de Meneses Silva pero tampoco de los duques de Pastrana. Aunque no aparece en las sentencias, quedó unido al condado de Cifuentes porque así lo ratifica Fernando VI en 1751 en un documento que después comentaré160 y allí lo incluye el manuscrito de la Renta del Tabaco al año siguiente ${ }^{161}$.

de Medinaceli; Gonzalo Fajardo de Silva, conde de Castro (biznieto de Juan de Silva, tercer conde de Cifuentes); Fernando Jacinto de Meneses Silva. En AHN, Nobleza, Osuna, carpeta de genealogías 3, documento 9, los pretendientes son: Gonzalo Fajardo de Silva, conde de Castro; Catalina de Silva Pacheco; Juan de Silva y Ribera, quinto marqués de Montemayor (nieto de un tataranieto de Juan de Silva, primer conde de Cifuentes); Julián de Cañas y Silva; Fernando Jacinto de Meneses Silva y su hijo Francisco; Antonio Juan Luis de la Cerda, séptimo duque de Medinaceli; Rodrigo de Silva, cuarto duque de Pastrana.

157. LaYNA SerRano, Francisco (1955): Historia de la villa condal de Cifuentes (Guadalajara), páginas 161 a 178 cuenta con muchos detalles este pleito. Todos los pretendientes al estado de Cifuentes involucrados en estos pleitos figuran en la genealogía adjunta para cuya elaboración he utilizado el Archivo de la Real Chancilleria de Valladolid (Registro de ejecutorias, caja 2604, número 32 y caja 2659, número 50), la sección Nobleza del Archivo Histórico Nacional (Osuna, legajo 2074, expediente 3, documento 1 y carpeta de genealogías 3, documento 9) y la obra de GutiÉRrez Coronel, Diego (1946 [1772]): Historia genealógica de la Casa de Mendoza, páginas 531 a 533. Un resumen de los datos esenciales en Layna Serrano, Francisco (1994 [1933]): Castillos de Guadalajara, páginas 312 a 314.

158. El 12 de enero de 1664 se expidió una carta ejecutoria en el pleito que trataba Rodrigo de Silva, cuarto duque de Pastrana con Fernando Jacinto de Meneses Silva, undécimo conde que fue de Cifuentes, su difunto hijo primogénito Francisco y su hijo segundo Pedro Félix José de Silva y Meneses, duodécimo conde de Cifuentes, sobre el mayorazgo de Cifuentes y la alferecía mayor de Castilla (Archivo de la Real Chancillería de Valladolid, Registro de ejecutorias, caja 2879, número 51); en 1674 Julián de Cañas y Silva salió al pleito, siendo admitido a él al año siguiente (Archivo de la Real Chancillería de Valladolid, Pleitos civiles, escribanía de Alonso Rodríguez, pleitos olvidados, caja 779, número 9, pie 1 , folios 2 a 3 y 14 y 14 vuelto); los últimos documentos de este pleito son de 1733 (Archivo de la Real Chancillería de Valladolid, Pleitos civiles, escribanía de Alonso Rodríguez, pleitos olvidados, caja 779, número 9).

159. Manuscrito de la Renta del Tabaco, provincia de Guadalajara, pueblo 501.

160. AHN, Nobleza, Cifuentes, caja 2, documentos 12 a 14.

161. Manuscrito de la Renta del Tabaco, provincia de Guadalajara, pueblo 518. 


\section{EVOLUCIÓN POSTERIOR (1644-1779)}

A Fernando Jacinto, undécimo conde de Cifuentes, le sucedieron su hijo Pedro Félix José de Silva y Meneses y su nieto Fernando de Silva y Meneses quien participó en la Guerra de Sucesión apoyando primero a Felipe V y después al archiduque Carlos. Don Carlos, titulándose «por la divina clemencia electo emperador de Romanos, siempre Augusto, rey de la Germania, de Castilla, de Aragón, de León, de las Dos Sicilias, de Jerusalem, de Ungría, de Bohemia, de Dalmacia, de Croacia, de Navarra, de Granada, de Toledo, de Valencia, de Galicia, de Mallorca, de Menorca, de Sevilla, de Cerdeña, de Córdova, de Córzega, de Murcia, de Jaén, de los Algarbes, de Algezira, de Gibraltar, de las yslas de Canaria, de las Yndias orientales y occidentales, yslas y tierra firme del mar Océano, archiduque de Austria, duque de Borgoña, de Brabante, de Milán, de Stiria, de Carintia, de Carniola, de Luxcemburg, de Wittemberg y Neopatria, príncipe de Suevia, marqués del Sacro Romano Ymperio, de Burgavia, de Moravia y de las dos Lusacias, conde de Abspurg, de Flandes, del Tiroy (sic), de Barcelona, de Ferreti, de Kiburgo, de Goricia, de Rosellón y Cerdaña, landgrave de Alsacia y conde de Gocceano, señor de la marca de Esclavonia, Puerto-Naón, Vizcaya, Molina, de las salinas de Trípoli y Mechlinia», le concedió la grandeza de España el 24 de abril de 1717 en Viena, donde el decimotercer conde de Cifuentes estaba exiliado $^{162}$. El 10 de octubre de 1725, aún en Viena, don Fernando eligió que esa grandeza de España quedara vinculada a su título de conde de Cifuentes, pues el emperador le había facultado para unirla a cualquiera de los que gozaba ${ }^{163}$. Ese mismo año el archiduque renunció a sus derechos a la Corona de España con la condición de que se amnistiara a sus fieles y se les reconocieran títulos y bienes ${ }^{164}$. Don Fernando murió en 1749 de vuelta en Cifuentes.

El 23 de septiembre de 1755 su hijo Juan de Silva y Meneses, decimocuarto conde de Cifuentes, se cubría en presencia de Fernando VI en el palacio del Buen Retiro de Madrid: «don Francisco Xavier de los Ríos, cavallero del orden de Santiago, del Consejo de Hazienda de Su Magestad y su secretario de cámara, zertifico que el rey nuestro señor señaló el día veinte y tres del corriente para que el excelentíssimo señor don Juan de Silba y Meneses, conde de Cifuentes, marqués de Alconcher, alférez mayor de Castilla, etcétera, executase la función de cubrirse por grande de España. Estando el rey en su real palacio de Buen Retiro en pie y cubierto en la pieza señalada para esta función y con asistencia de los excelentíssimos señores duque de Alba, conde de Altamira, duque de el Arco, marqués de Villafranca, conde de Aguilar y otros muchos, fue llamado por mi el referido señor don Juan de Silba y Meneses, conde de Cifuentes, y conducido por el excelentíssimo señor duque de Medinasidonia, su padrino, a la pieza donde Su Magestad estaba. Luego que huvo hecho las tres reverencias,

162. AHN, Nobleza, Cifuentes, caja 2, documento 1 , folios 1 a 6 vuelto.

163. AHN, Nobleza, Cifuentes, caja 2, documento 1, folios 7 a 8 .

164. Layna Serrano, Francisco (1955): Historia de la villa condal de Cifuentes (Guadalajara), página 215. 
le mandó el rey en presencia de todos se cubriese y el dicho señor don Juan de Silbay Meneses se cubrió como conde de Zifuentes según y al tiempo que lo hacen los grandes de primera clase, haviendo precedido todas las ceremonias de honor que se acostumbran en semejantes casos $\rangle^{165}$.

Siendo aún niño bajo la tutela de su madre Luisa de Rávata (hija de los condes alemanes de Stralsoldo), Juan de Silva Meneses se benefició de una provisión de Fernando VI de 1751 que eximía sus señoríos de ser reintegrados a la Corona por la Junta de Incorporación. Para ello doña Luisa presentó la confirmación que dio Juan Il en Alcalá de Henares del 28 de febrero de 1436 de la merced que había hecho de Cifuentes a Juan de Silva el 10 de marzo de 1431 y a la que ya me referí al describir la incorporación de este señorío a los Silva: «se acudió a la nominada secretaría en el día doze de marzo de este año por parte de la condesa viuda de Zifuentes como tutora y curadora de la persona y bienes de don Juan de Silba, su hijo menor, conde actual de Zifuentes, haciendo presentazión de un privilegio rodado del señor rey don Juan el segundo, expedido en veinte y ocho de febrero del año de mil quatrocientos treinta y seis por el qual resultó que en consecuencia de lo que Su Magestad prometió al adelantado Alfonso Tenorio, padre de don Juan de Silva, su criado y notario mayor del reyno de Toledo, y atendiendo a los muchos, buenos y leales servicios que hicieron aquél y sus antepasados al señor rey don Enrique, su padre, y a los demás señores reyes, sus predecesores, y a los que havía hecho y hacía a Su Magestad de cada día el nominado don Juan, por su real privilegio de diez de marzo del año de mil quatrocientos y treinta y uno, le hizo merced, gracia y donación irrebocable de la villa de Zifuentes y su tierra, con su castillo y fortaleza, término y distrito y con la Justicia y jurisdicción civil y criminal, alta, baja, mero mixto imperio, escrivanías, portazgos, martiniegas, penas, calumnias, rentas, pechos, derechos, vasallos, vezinos y moradores de ella y de su tierra con sus términos, egidos, dehesas, prados, pastos, montes, ríos y aguas corrientes, estantes y manantes y con todo lo demás al señorio de dicha villa y su tierra perteneciente en qualquiera manera, a excepción de las alcavalas, tercias, pedido, monedas y los mineros de oro, plata y otros metales, con la mayoría de la Justicia y las otras cosas pertenecientes a la suprema regalia, para él, sus herederos y succesores, por juro de heredad para siempre jamás, con facultad de disponer de todo a su voluntad y tomar y aprehender la posesión de la referida villa y su tierra, términos, vasallos y jurisdicción, rentas y demás pechos y derechos. [...] El qual, a instancia del nominado don Juan de Silva, confirmó el propio señor rey en forma especifica y haciéndole en caso necesario nueba gracia y merced de lo referido por el citado de veinte y ocho de febrero de mil y quatrozientos treinta y seis en que se insertó la antecedente» ${ }^{166}$.

Este documento es interesante no sólo por confirmar la fecha en que se donó Cifuentes a Juan de Silva sino también porque recoge todos los derechos, pechos y nombramientos de cargos que correspondían a los condes en varios lugares de su

165. AHN, Nobleza, Cifuentes, caja 2, documento 1, folios 9 a 10.

166. AHN, Nobleza, Cifuentes, caja 2, documento 12, folios 2 vuelto a 4 . 
señorío (Cifuentes, Trillo, Ruguilla y Valderrebollo) y confirma que eran dueños de Barriopedro: «pertenecia al nominado conde la jurisdicción de dich a villa de Zifuentes con el nombramiento de alcalde mayor, corregidor, theniente y la alcaldía de su castillo y fortaleza y las elecciones de justicias, que a proposición de la misma villa se hazen en cada un año, de dos alcaldes ordinarios, uno por el estado noble y otro por el general, dos regidores en la propia conformidad, un alguacil mayor, un escrivano de Ayuntamiento que se nombra o rehelige annualmente, dos diputados, dos alcaldes de la Hermandad, dos jurados, un camarero del pósito, y que igualmente le pertenece el nombramiento de tres escrivanías del numero de ella y el derecho de portazgo y martiniega con el de presente y presencia, que se reduce a una gratificación que hace la villa, en especie, de géneros comestibles como regalo de Navidad al tiempo de llevarle las proposiciones para la elección de justicias; [...] y que asi mismo le pertenece la jurisdicción de la villa de Trillo con el nombramiento annual de dos alcaldes ordinarios, dos de la Hermandad, dos regidores, dos jurados y diputados, un camarero, escribano de Ayuntamiento, un alguazil mayor y escrivanía de ella, en la conformidad que en la de Cifuentes, con el derecho de portazgo y el de presente y presencia; y que en la propia forma le toca la jurisdicción de la villa de Ruguilla con la elección de Justicias de ella, que se compone de dos alcaldes ordinarios, dos regidores, un alcalde de la Hermandad, alguazil mayor y escribano de fechos por no haver capacidad para mantenerle del número; y que igualmente le pertenece la jurisdicción de la villa de Balderrebollo y elección de justicias, compuesta de dos alcaldes ordinarios, dos regidores, un alcalde de la Hermandad, un alguacil mayor y nombramiento de escribano de fechos en la conformidad que en la de Ruguilla; y que la misma jurisdicción y elección de justicias de dos alcaldes ordinarios, dos regidores, alguacil y escribano de fechos, le toca en la villa de Barriopedro como en las dos antecedentes $\rangle^{167}$. Faltan referencias a Val de San García y Fuentepinilla, lugares que se incluían entre las «aldeas antiguas» de Cifuentes y a donde estaban directamente sometidas.

Más difícultades entraña la ausencia de Huetos que no pertenecía a esa tierra vieja cifontina sino que fue comprado en 1441 y que en el manuscrito de la Renta del Tabaco, elaborado al año siguiente de este documento, se atribuye al realengo ${ }^{168}$ a pesar de que las sentencias de 1620 y 1644 lo habían adjudicado a los condes de Cifuentes ${ }^{169}$. Pero en el Archivo de la Real Chancillería de Valladolid se conserva la documentación de un pleito iniciado en 1779 entre Juan de Silva y Meneses, decimocuarto conde de Cifuentes, y los vecinos y el concejo de Huetos sobre el pago de un derecho de 28 fanegas de grano y en él aún figura dentro del señorío de Cifuentes («digo que al estado de Cifuentes de que mi parte es poseedor y a que se halla incorporada la villa de Huetos pertenezen varias rentas de tierras, pensiones, tributos y otros derechos y entre ellos

167. AHN, Nobleza, Cifuentes, caja 2, documento 12, folios 5 a 6 vuelto.

168. Manuscrito de la Renta del Tabaco, provincia de Guadalajara, pueblo 502.

169. Layna Serrano, Francisco (1955): Historia de la villa condal de Cifuentes (Guadalajara), páginas 176 y 177. 
el de veinte y ocho fanegas de trigo y centeno por mitad que se han satisfecho siempre a dicho mi parte y sus antecesores por los vecinos de dicha villa de Huetos» ${ }^{170}$ ), por 10 que el manuscrito debe estar errado en este punto.

170. Archivo de la Real Chancillería de Valladolid, Pleitos civiles, escribanía de Fernando Alonso, fenecidos, caja 2968, número 5 , folio 1 . 


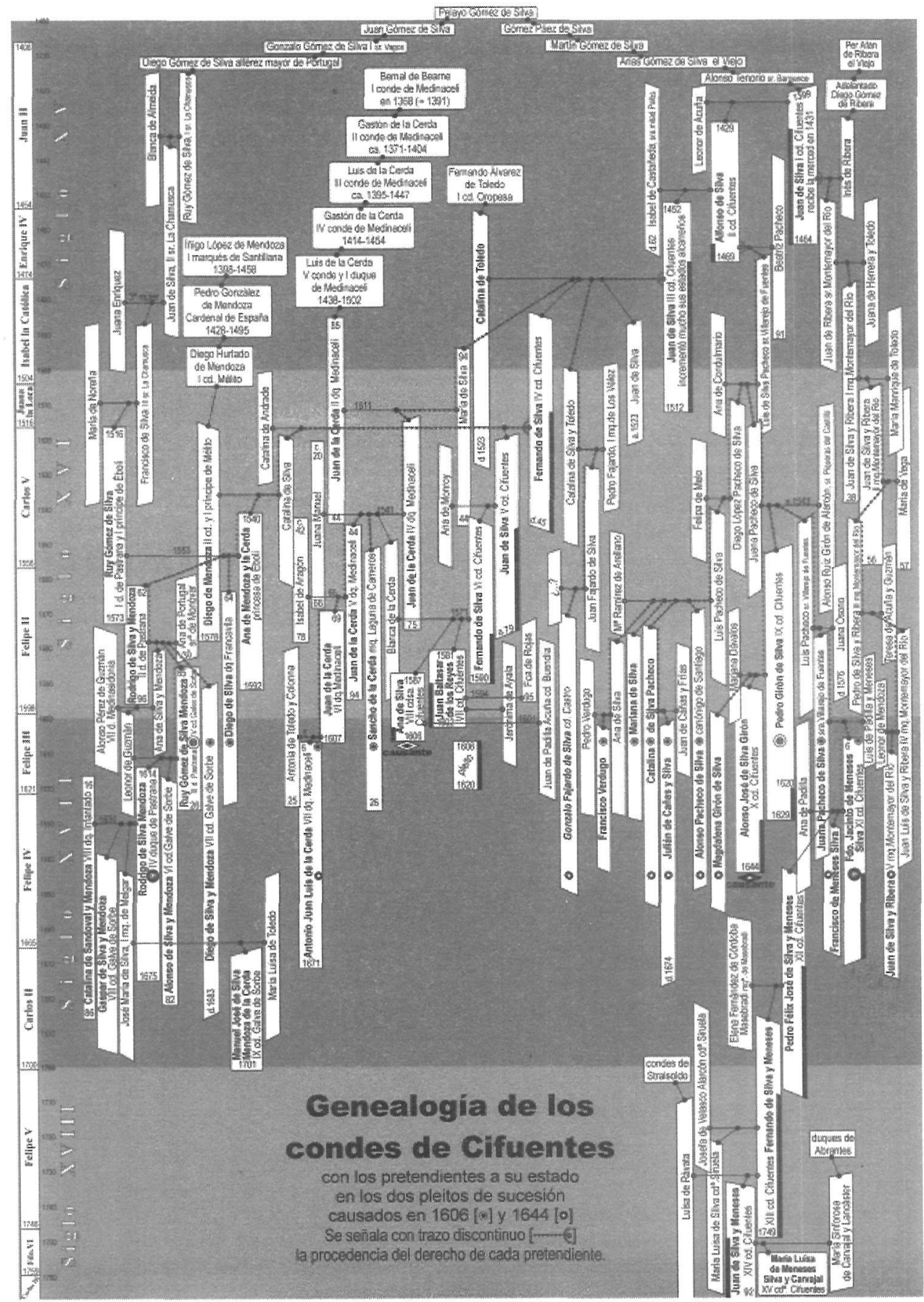



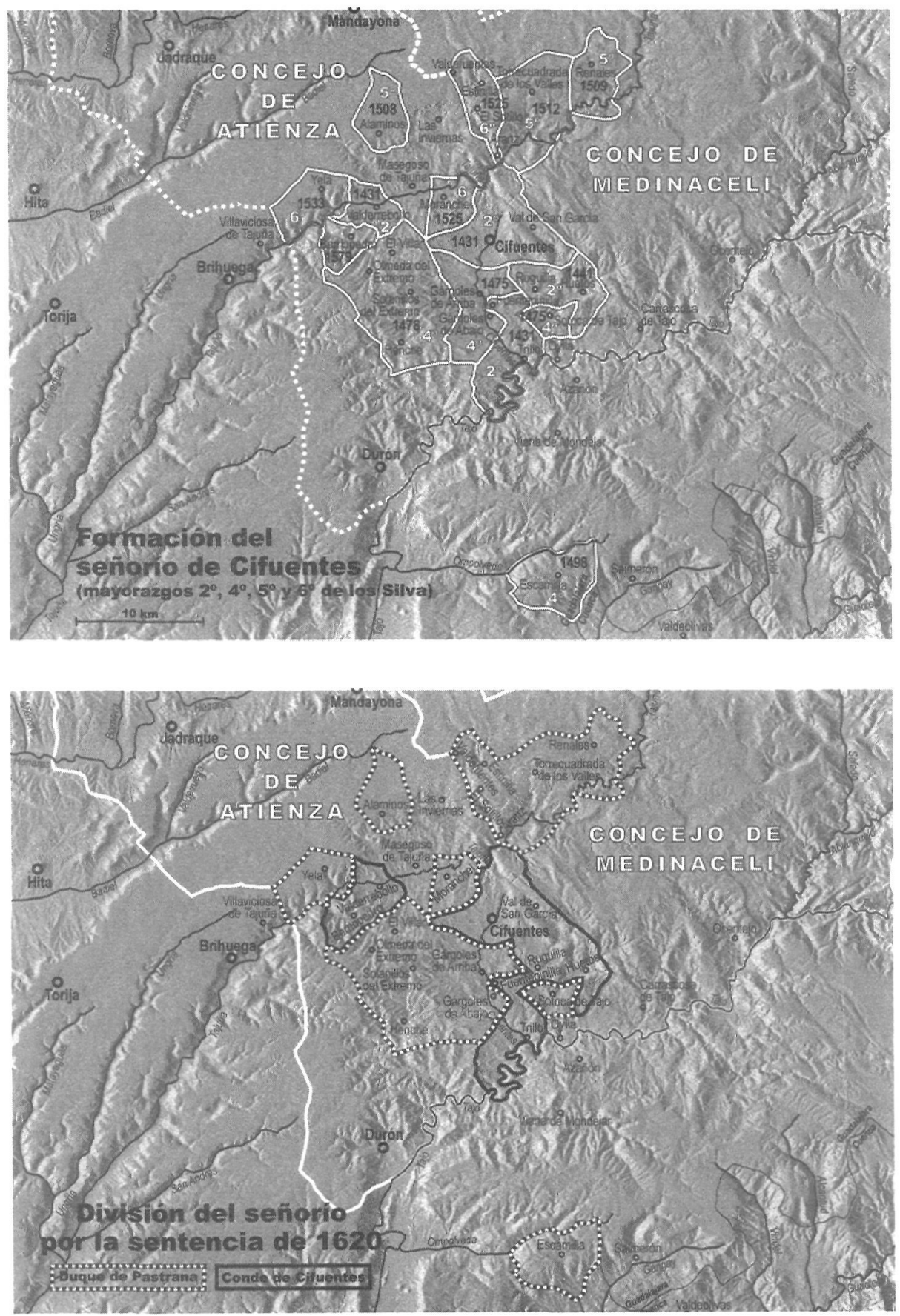